IZA DP No. 4536

A Structural Analysis of Disappointment Aversion in a Real Effort Competition

David Gill

Victoria Prowse

October 2009 


\title{
A Structural Analysis of Disappointment Aversion in a Real Effort Competition
}

\author{
David Gill \\ University of Southampton \\ Victoria Prowse \\ University of Oxford \\ and IZA

\section{Discussion Paper No. 4536 \\ October 2009} \\ IZA \\ P.O. Box 7240 \\ 53072 Bonn \\ Germany \\ Phone: +49-228-3894-0 \\ Fax: +49-228-3894-180 \\ E-mail: iza@iza.org
}

Any opinions expressed here are those of the author(s) and not those of IZA. Research published in this series may include views on policy, but the institute itself takes no institutional policy positions.

The Institute for the Study of Labor (IZA) in Bonn is a local and virtual international research center and a place of communication between science, politics and business. IZA is an independent nonprofit organization supported by Deutsche Post Foundation. The center is associated with the University of Bonn and offers a stimulating research environment through its international network, workshops and conferences, data service, project support, research visits and doctoral program. IZA engages in (i) original and internationally competitive research in all fields of labor economics, (ii) development of policy concepts, and (iii) dissemination of research results and concepts to the interested public.

IZA Discussion Papers often represent preliminary work and are circulated to encourage discussion. Citation of such a paper should account for its provisional character. A revised version may be available directly from the author. 
IZA Discussion Paper No. 4536

October 2009

\section{ABSTRACT}

\section{A Structural Analysis of Disappointment Aversion in a Real Effort Competition*}

We develop a novel computerized real effort task, based on moving sliders across a screen, to test experimentally whether agents are disappointment averse when they compete in a real effort sequential-move tournament. Our theory predicts that a disappointment averse agent, who is loss averse around her endogenous expectations-based reference point, responds negatively to her rival's effort. We find significant evidence for this discouragement effect, and use the Method of Simulated Moments to estimate the strength of disappointment aversion on average and the heterogeneity in disappointment aversion across the population.

JEL Classification: C91, D03

Keywords: disappointment aversion, loss aversion, reference-dependent preferences, reference point adjustment, expectations, tournament, real effort experiment, slider task

Corresponding author:

Victoria Prowse

University of Oxford

Department of Economics

Manor Road Building

Manor Road

Oxford, OX1 3UQ

United Kingdom

E-mail: victoria.prowse@economics.ox.ac.uk

\footnotetext{
Financial support from the George Webb Medley Fund and a Southampton School of Social Sciences Small Grant is gratefully acknowledged. We also thank the Nuffield Centre for Experimental Social Sciences for hosting our experiments.
} 
The sudden disappointment of a hope leaves a scar which the ultimate fulfilment of that hope never entirely removes. ${ }^{1}$

England fullback Delon Armitage is determined to put his misery at being overlooked by the British 83 Irish Lions behind him when he runs out to face Argentina at Old Trafford on Saturday ... The occasion will not be lost on Armitage, although he is struggling to get past the disappointment of missing out on a Lions call after an excellent first Test season ... 'I was really, really disappointed about it,' he said. 'I still need to get over it a little bit.' 2

\section{Introduction}

Disappointment at doing worse than expected can be a powerful emotion. This emotion may be particularly intense when the disappointed agent exerted effort in competing for a prize, thus raising her expectation of winning. Furthermore, a rational agent who anticipates possible disappointment will optimize taking into account the expected disappointment arising from her choice.

In this paper we use a laboratory experiment to test whether agents are disappointment averse when they compete in a real effort tournament. In particular, we test whether our subjects are loss averse around reference points given by endogenous expectations. Pairs of subjects complete a novel computerized real effort task, called the "slider task", which involves moving sliders across a screen. The First Mover completes the task, followed by the Second Mover, who observes the First Mover's effort before choosing how hard to work. ${ }^{3}$ A money prize is awarded to one of the pair members based on the pair's relative work efforts and some element of chance which we control. After each repetition, the subjects are re-paired. If agents care only about money and the cost of effort then the Second Mover's work effort should not depend on the effort of the First Mover. However, as predicted by our theory of disappointment, the experimental data show a discouragement effect: the Second Mover shies away from working hard when she observes that the First Mover has worked hard, and tends to work relatively hard when she observes that her competitor has put in low effort.

Our contribution is three-fold: methodological; theoretical; and empirical. From a methodological perspective, we develop a novel real effort task designed to facilitate robust statistical inference. Early experiments implementing costly activities used a monetary cost function which mimics effort by specifying output as a function of how much money subjects contribute (e.g., Bull et al., 1987, in a tournament context). Increasingly, laboratory experiments have featured real effort tasks. ${ }^{4}$ Real effort generates greater external validity, but makes precise quantification difficult (Falk and Fehr, 2003). The main advantage of our slider task is that it allows a fine and accurate measure of effort over a short time scale. Thus we interpret performance in the task as effort exerted and we can use repeated observations of the same subjects to control for

\footnotetext{
${ }^{1}$ Thomas Hardy, as quoted by Gibson (1996, p. 74).

${ }^{2}$ ESPN Scrum, 4 June 2009, www.scrum.com/england/rugby/story/97635.html

${ }^{3}$ We use a sequential tournament to give clean identification, rather than because most competitive situations involve sequential effort choices.

${ }^{4}$ See Section 2.1.2 for examples of different real effort tasks. Recently experiments involving real effort tournaments have become popular (e.g., van Dijk et al., 2001; Gneezy et al., 2003; Niederle and Vesterlund, 2007; Carpenter et al., 2007; Charness and Villeval, 2009).
} 
learning-by-doing and persistent unobserved heterogeneity. We believe that our task will prove valuable to researchers in designing future experiments with real effort.

From a theoretical perspective, we extend disappointment aversion to situations in which agents compete. Existing models of disappointment aversion (e.g., Bell, 1985; Loomes and Sugden, 1986; Gul, 1991; Shalev, 2000; Delquié and Cillo, 2006a, 2006b; Köszegi and Rabin, 2006,2007 ) build on the idea that agents are sensitive to deviations from what they expected to receive. We model disappointment aversion as loss aversion around an agent's expected payoff, so losses relative to this expectation are more painful than equal-sized gains are pleasurable. ${ }^{5}$ In our competitive framework, this expected payoff is determined endogenously by the agents' effort choices. Thus we model agents as holding reference-dependent preferences with an endogenous reference point given by choice-acclimating (Köszegi and Rabin, 2007) expectations, and we assume that agents anticipate the impact of effort on their reference point.

Our theory predicts an empirically testable discouragement effect whereby the Second Mover responds negatively to the First Mover's effort. Thus First and Second Movers' efforts are strategic substitutes. This discouragement effect becomes more powerful in the strength of disappointment aversion, measured by the size of the kink in utility induced by loss aversion, and in the value of the prize. A disappointment averse Second Mover becomes discouraged even though we impose probabilities of winning the prize which are linear in the difference in the agents' efforts, so that, in the canonical tournament model with a separable cost of effort, the First Mover's effort has no effect on the Second Mover's marginal incentives. Note that the endogeneity of the reference point is crucial. Most of the literature on loss aversion assumes a fixed reference point, but with such a reference point, even if given by a prior expectation, the standard model predicts no discouragement effect.

From an empirical perspective, we offer evidence of disappointment aversion from a linear random effects panel regression and from structural estimation using the Method of Simulated Moments. We find significant evidence of disappointment aversion. The reduced form analysis shows that subjects' behavior in our experiment is inconsistent with the standard model, but instead exhibits the discouragement effect predicted by our theory of disappointment. Additionally, we use structural modeling to estimate the strength of disappointment aversion on average and the heterogeneity in disappointment aversion across the population. Both estimation methods exploit identifying variation obtained from the properties of the slider task together with our experimental design. Specifically, the value of the prize is drawn randomly each time a First and Second Mover are paired, while the fineness of our measure of effort allows us to observe precisely how Second Movers respond to the prize and the effort choice of the First Mover they are paired with.

Our empirical results address two important open questions in the literature on referencedependent preferences: (i) what constitutes agents' reference points?; and (ii) how quickly do these reference points adjust to new circumstances? Our analysis provides evidence that when agents compete they have reference points given by their expected monetary payoff and that an agent's reference point adjusts essentially instantaneously to her own effort choice and that of

\footnotetext{
${ }^{5}$ Loss aversion is a fundamental component of Kahneman and Tversky (1979)'s Prospect Theory. Kahneman and Tversky (2000) collect a number of papers providing empirical support for loss aversion in numerous different contexts, while DellaVigna (2009) surveys some more recent evidence.
} 
others.

Our work is complementary to that of Abeler et al. (2009) and Crawford and Meng (2009) who also find evidence for expectations-based reference-dependent preferences in the context of effort provision. Abeler et al. run a laboratory experiment with a non-competitive design in which subjects have a $50 \%$ chance of being paid piece-rate and a $50 \%$ chance of receiving a fixed payment, and show that effort increases in the fixed payment. Abeler et al. do not estimate any structural parameters, while we are able to estimate the strength of disappointment aversion. Crawford and Meng use field data on taxi driver labor supply to estimate the strength of loss aversion around rational expectations-based daily income and hours targets. ${ }^{6}$ In contrast to our model, the reference point is taken to be fixed when the agent chooses how hard to work. Our paper is also related to the existing empirical literature on disappointment aversion in the absence of effort provision. A number of papers test for disappointment aversion using choices over, or bids for, lotteries. Loomes and Sugden (1987) provide an early example, while recent instances include Choi et al. (2007) and Sonsino (2008).

Finally, the psychology literature also supports the thesis that agents' emotional responses to the outcomes of gambles include disappointment and elation, that agents anticipate these emotions when choosing between gambles and that exerting effort, by increasing the likelihood of a good outcome, intensifies disappointment (Mellers et al., 1999; van Dijk et al., 1999).

The rest of the paper is structured as follows. Section 2 describes the slider task and the design of the experiment. Section 3 develops our theory of disappointment aversion when agents compete. Section 4 presents the empirical analysis. Section 5 concludes. Appendix A derives proofs not included in the main text. Appendix B provides further details about the structural estimation method and the model's goodness of fit. Finally, Appendix C lays out the instructions provided to the experimental subjects.

\section{Experimental Design}

We ran 6 experimental sessions at the Nuffield Centre for Experimental Social Sciences (CESS) in Oxford, all conducted on weekdays at the same time of day in late February and early March 2009 and lasting approximately 90 minutes. $^{7} 20$ student subjects (who did not report Psychology or Economics as their main subject of study) participated in each session, with 120 participants in total. The subjects were drawn from the CESS subject pool which is managed using the Online Recruitment System for Economic Experiments (ORSEE). The experimental instructions (Appendix C) were provided to each subject in written form and were read aloud to the subjects. Seating positions were randomized. To ensure subject-experimenter anonymity, actions and payments were linked to randomly allocated Participant ID numbers. Each subject was paid a show-up fee of $£ 4$ and earned an average of a further $£ 10$ during the experiment (all payments were in Pounds sterling). At the end of the experiment, subjects were asked to report their gender (but could withhold this information). Subjects were paid privately in cash by the laboratory administrator. The experiment was programmed in z-Tree (Fischbacher, 2007).

\footnotetext{
${ }^{6}$ Camerer et al. (1997) and Doran (2009) also find evidence of taxi driver loss aversion.

${ }^{7}$ We also ran one pilot session without any monetary incentives whose results are not reported here.
} 


\subsection{The Slider Task}

Before setting out the experimental procedure, we first describe the novel computerized real effort task, which we call the "slider task", that we designed for the purpose of this experiment and explain its advantages in relation to the existing stock of real effort tasks.

\subsubsection{Description of the Slider Task}

The slider task consists of a single screen displaying a number of sliders. The number and position of the sliders on the screen does not vary across experimental subjects or across repetitions of the task. A schematic representation of a single slider is shown in Figure 1. When the screen containing the effort task is first displayed to the subject all of the sliders are positioned at 0 , as shown for a single slider in Figure 1(a). By using the mouse, the subject can position each slider at any integer location between 0 and 100 inclusive. Each slider can be adjusted and readjusted an unlimited number of times and the current position of each slider is displayed to the right of the slider. The subject's "points score" in the task is the number of sliders positioned at 50 at the end of the allotted time. As explained in Section 2.1.2, we interpret a subject's point score as effort exerted in the task. Figure 1(b) shows a correctly positioned slider. As the task proceeds, the screen displays the subject's current points score and the amount of time remaining.

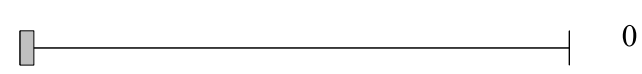

(a) Initial position.

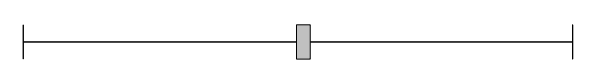

50

(b) Positioned at 50

Figure 1: Schematic representation of a slider.

The number of sliders and task length can be chosen by the experimenter. In this experiment we used 48 sliders and an allotted time of 120 seconds. The sliders were displayed on 22 inch widescreen monitors with a 1680 by 1050 pixel resolution. To move the sliders, the subjects used 800 dpi USB mice with the scroll wheel disabled. ${ }^{8}$ Figure 2 shows a screen of sliders as shown to the subject in the laboratory. In this example, the subject has positioned three of the sliders at 50 and a points score of 3 is shown at the top of the screen. A fourth slider is currently positioned at 33 and this slider does not contribute to the subject's points score as it is not positioned correctly. To ensure that all the sliders are equally difficult to position correctly, the 48 sliders are arranged on the screen such that no two sliders are aligned exactly one under the other. This prevents the subject being able to position the higher slider at 50 and then easily position the lower slider by copying the position of the higher slider.

\subsubsection{Advantages of the Slider Task}

The slider task has a number of desirable attributes. First, the slider task is simple to communicate and to understand, and does not require or test pre-existing knowledge. Second, unlike solving mathematical problems (Sutter and Weck-Hannemann, 2003), counting, decoding or

\footnotetext{
${ }^{8}$ The keyboards were also disabled to prevent the subjects using the arrow keys to position the sliders.
} 


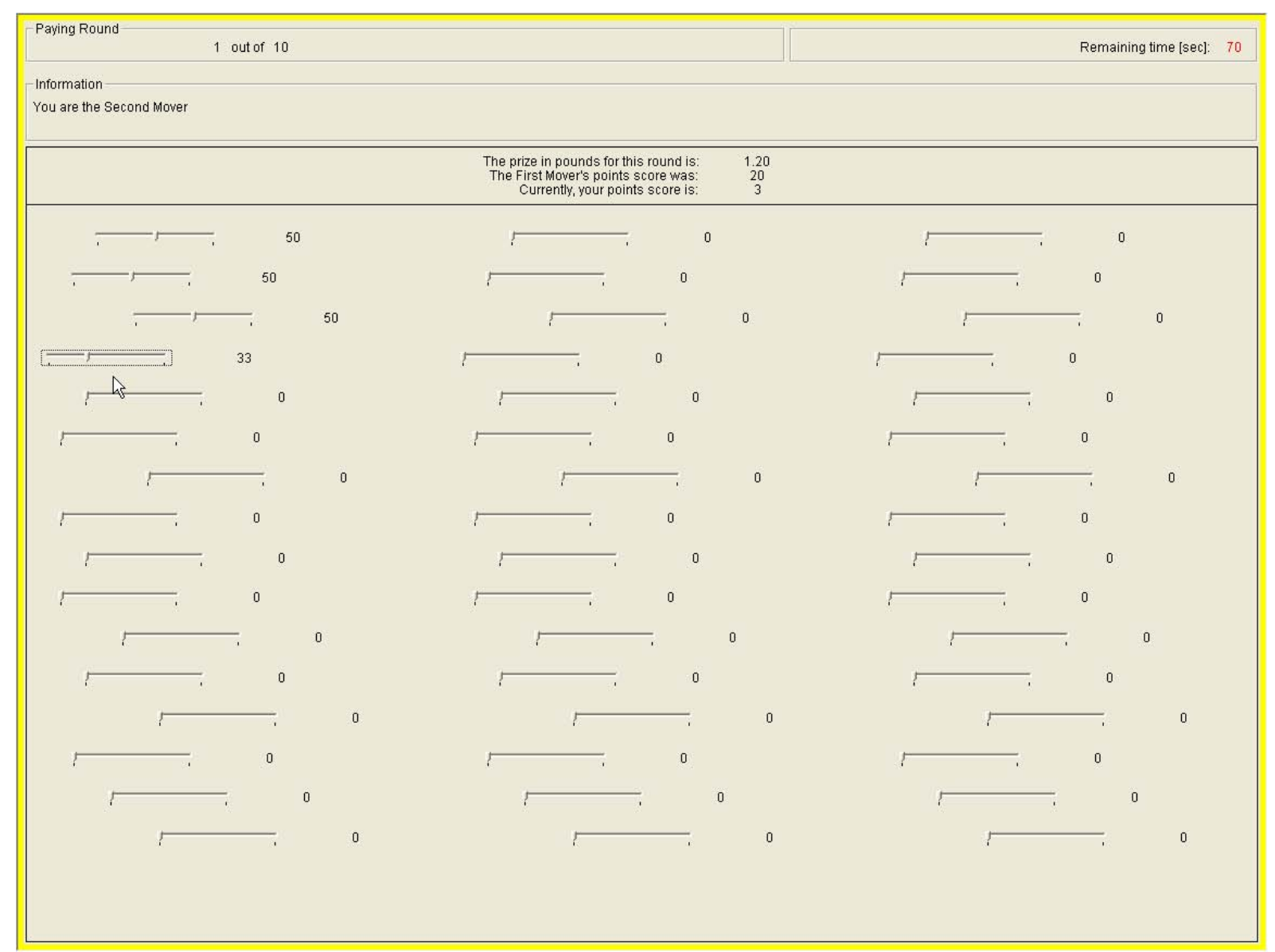

Notes: The screen presented here is slightly squarer than the one seen by our subjects.

Figure 2: Screen showing 48 sliders.

entering strings of characters (Chow, 1983), solving word games (Burrows and Loomes, 1994), answering general knowledge questions (Hoffman et al., 1994), negotiating mazes (Gneezy et al., 2003) or performing numerical optimization (van Dijk et al., 2001), the slider task is identical across repetitions. Third, the task allows a fine measure of performance and involves little randomness, so the number of correctly positioned sliders corresponds closely to the effort exerted by the subject. Thus we interpret a subject's point score as effort exerted in the task. Fourth, there is no scope for guessing, which complicates the design and interpretation of some existing tasks such as those based on counting characters or numerical optimization.

These attributes are also shared by the envelope filling task (Konow, 2000), in which subjects stuff real envelopes with letters. Crucially, however, the slider task allows a fine measure of effort within a short time scale. Furthermore, because the task is computerized, it is easy to implement and allows flexible real-time subject interactions. In Section 4 we see that with 48 sliders and an allotted time of 120 seconds, measured effort varies from 0 to over 40 . Thus substantial variation in behavior can be observed, and by getting subjects to repeat the identical task many times the experimenter can control for persistent unobserved heterogeneity using panel data methods. This allows robust statistical inference. For example, we use repeated observations of the same subjects to estimate the distribution of effort costs, enabling structural estimation of the strength of disappointment aversion on average and the heterogeneity in disappointment aversion across the population. Thus the task's design overcomes the principal drawback of 
using real effort up to now, namely that 'Since the experimenter does not know the workers' effort cost, it is not possible to derive precise quantitative predictions" (Falk and Fehr, 2003, p. 404).

\subsection{Experimental Procedure}

In every session 10 subjects were told that they would be a "First Mover" and the other 10 that they would be a "Second Mover" for the duration of the session. Each session consisted of 2 practice rounds followed by 10 paying rounds.

In every paying round, each First Mover was paired anonymously with a Second Mover. Each pair's prize was chosen randomly from $\{£ 0.10, £ 0.20, \ldots, £ 3.90\}$ and revealed to the pair members. The First and Second Movers then completed our slider task sequentially, with the Second Mover discovering the points score of the First Mover she was paired with before starting the task. As explained in Section 2.1.1, we used a slider task with 48 sliders and an allotted time of 120 seconds. During the task, a number of pieces of information appeared at the top of the subject's screen: the round number; the time remaining; whether the subject was a First or Second Mover; the prize for the round; and the subject's points score in the task so far. If the subject was a Second Mover, she also saw the points score of the First Mover. Figure 2 provides an example of the screen visible to the Second Movers.

The probability of winning the prize for each pair member was 50 plus her own points score minus the other pair member's points score, all divided by 100. Thus, we imposed winning probabilities linear in the difference of the points scores, with equal points scores giving equal winning probabilities, while an increase of 1 in the difference raised the chance of winning by 1 percentage point for the pair member with the higher points score. The probability of winning function was explained verbally and using Table 6 . At the end of the round, the subjects saw a summary screen showing their own points score, the other pair member's points score, their probability of winning the prize given the respective points scores, the prize for the round and whether they were the winner or loser of the prize in that round.

After each paying round the subjects were re-paired according to Cooper et al. (1996)'s "no contagion" matching algorithm (as used recently by, e.g., Dal Bó, 2005). This rotation-based algorithm ensures that not only do the same subjects never meet each other more than once, but that each round is truly one-shot in the sense that a given subject's actions in one round cannot influence, either directly or indirectly, the actions of other subjects that the subject is paired with later on. The explanation to the subjects in the experimental instructions provides further detail.

Before starting the paying rounds, the subjects played 2 practice rounds to gain familiarity with the task and procedure and to give opportunities for questions. To prevent contamination the subjects were made aware that during the practice rounds they were playing against automata who behaved randomly. At the end of each practice round, the subjects were informed of what their probability of winning would have been given the respective points scores, but were not told that they had won or lost in that round, and no prizes were awarded. We do not include the practice rounds in the econometric analysis. 


\section{Theoretical Predictions}

In this Section we provide a theoretical model of the behavior of a generic pair of First and Second Movers competing for a prize $v$ in a particular round. After describing the model, we show that in the absence of disappointment aversion the Second Mover's effort does not depend on the First Mover's effort, while a disappointment averse Second Mover will respond negatively to the effort choice of the First Mover.

\subsection{One-Shot Theory Model}

Two agents compete to win a fixed prize of monetary value $v>0$ in a rank-order tournament, choosing their effort levels sequentially. The First Mover chooses her effort level $e_{1}$ from an action space $\mathcal{A} \subseteq[0, \bar{e}]$ which can be discrete or continuous. The Second Mover observes $e_{1}$ before choosing her effort level $e_{2}$ from $\mathcal{A}$. As noted in Section 2.1.2, we interpret a subject's points score in the slider task as effort exerted. Agent $i$ 's probability of winning the prize $P_{i}\left(e_{i}, e_{j}\right)$ increases linearly in the difference between her own effort, $e_{i}$, and the other agent's effort, $e_{j}$. Assuming symmetry of the probability of winning functions,

$$
P_{i}\left(e_{i}, e_{j}\right)=\frac{e_{i}-e_{j}+\gamma}{2 \gamma}
$$

with $\gamma \geq \bar{e}$ to ensure that $P_{i} \in[0,1] .^{9}$ Throughout we focus on the behavior of the Second Mover conditional on the First Mover's effort $e_{1}$.

\subsection{No Disappointment Aversion}

Applying the canonical model in the tournament literature, the Second Mover's utility $U_{2}$ is separable into utility $u_{2}\left(y_{2}\right)$ from her tournament payoff $y_{2} \in\{0, v\}$, which we call her material utility, and her cost of effort $C_{2}\left(e_{2}\right),{ }^{10}$ so

$$
U_{2}\left(y_{2}, e_{2}\right)=u_{2}\left(y_{2}\right)-C_{2}\left(e_{2}\right)
$$

The underlying assumption is that because the (non-monetary) effort cost is sunk before the winner of the tournament is determined, the effort choice does not affect risk preferences over the monetary payoff from the tournament. Separability implies that the Second Mover's expected utility is given by

$$
\begin{aligned}
E U_{2}\left(e_{2}, e_{1}\right) & =P_{2}\left(e_{2}, e_{1}\right) u_{2}(v)+\left(1-P_{2}\left(e_{2}, e_{1}\right)\right) u_{2}(0)-C_{2}\left(e_{2}\right) \\
& =\left(u_{2}(v)-u_{2}(0)\right)\left(\frac{e_{2}-e_{1}+\gamma}{2 \gamma}\right)+u_{2}(0)-C_{2}\left(e_{2}\right) .
\end{aligned}
$$

As the winning probabilities are linear in the difference in efforts, the First Mover's effort $e_{1}$ has no effect on the marginal impact of the Second Mover's effort $e_{2}$ on her probability of winning.

\footnotetext{
${ }^{9}$ Che and Gale (2000) call this a piece-wise linear difference-form success function.

${ }^{10}$ In their related work, Abeler et al. (2009) and Crawford and Meng (2009) make equivalent separability assumptions.
} 
Thus the Second Mover's marginal utility with respect to her own effort does not depend on $e_{1}$, giving the following result.

Proposition 1 In the absence of disappointment aversion the Second Mover's optimal effort $e_{2}^{*}$ (or set of optimal efforts) does not depend on the First Mover's effort $e_{1}$.

Note that we have not imposed any concavity or differentiability assumptions on $u_{2}\left(y_{2}\right)$ (and nor have we assumed anything about the shape of $\left.C_{2}\left(e_{2}\right)\right)$. Thus the result continues to hold if the Second Mover is loss averse around a fixed reference point (Section 3.3 elaborates) or exhibits any degree of risk aversion over her monetary payoff. The result also holds if $u_{2}\left(y_{2}\right)$ incorporates an impact of winning or losing on the utility function in any later tournaments, e.g., via changes in wealth or the reference point.

\subsection{Disappointment Aversion}

Models of disappointment aversion (e.g., Bell, 1985; Loomes and Sugden, 1986; Gul, 1991; Shalev, 2000; Delquié and Cillo, 2006a, 2006b; Köszegi and Rabin, 2006, 2007) build on the idea that agents are sensitive to deviations from their expectations, suffering a psychological loss when they receive less than expected and experiencing elation when they receive more. Furthermore, agents anticipate these losses and gains when deciding how to behave.

We follow most of the literature in embedding disappointment aversion in a loss aversiontype framework. ${ }^{11}$ Suppose that the Second Mover compares her material utility $u_{2}\left(y_{2}\right)$ to a reference level of utility $R_{2}$, suffering losses when $u_{2}\left(y_{2}\right)$ is less than this reference point and enjoying gains when $u_{2}\left(y_{2}\right)$ exceeds the reference point. Specifically, total utility $U_{2}$ is given by

$$
U_{2}\left(y_{2}, R_{2}, e_{2}\right)=u_{2}\left(y_{2}\right)+\mathbf{1}_{u_{2}\left(y_{2}\right) \geq R_{2}} G_{2}\left(u_{2}\left(y_{2}\right)-R_{2}\right)+\mathbf{1}_{u_{2}\left(y_{2}\right) \leq R_{2}} L_{2}\left(u_{2}\left(y_{2}\right)-R_{2}\right)-C_{2}\left(e_{2}\right),
$$

where the loss function $L_{2}(x)<0$ for $x<0$, the gain function $G_{2}(x) \geq 0$ for $x>0$ and $G_{2}(0)=L_{2}(0)=0$. The utility arising from the comparison of $u_{2}\left(y_{2}\right)$ to the reference point is termed gain-loss utility. The Second Mover is said to be loss averse if losses due to downward departures from the reference point are more painful than equal-sized upward departures are pleasurable, i.e., $G_{2}(x)<\left|L_{2}(-x)\right|$ for all $x>0$. The Second Mover is first-order loss averse if she is loss averse in the limit as the deviations from the reference point go to zero, i.e., $\lim _{x \uparrow 0} L_{2}^{\prime}(x)>\lim _{x \downarrow 0} G_{2}^{\prime}(x)$, assuming differentiability of gain-loss utility except at the kink where $x=0$.

By modeling each tournament as a one-shot interaction, we are assuming that our subjects frame each tournament narrowly, i.e., they compare the outcome of each tournament to their reference point in isolation. Models and tests of loss aversion generally incorporate narrow framing, either implicitly or explicitly (DellaVigna, 2009). Barberis et al. (2006) provide evidence that attitudes towards small gambles can only be explained by first-order loss aversion together

\footnotetext{
${ }^{11}$ Instead, Gul (1991) uses probability weighting, while Loomes and Sugden (1986) insist on the differentiability of utility. Kahneman and Tversky (1979)'s Prospect Theory incorporates a loss averse value function defined only over losses and gains relative to the reference point, while we follow the disappointment aversion literature in defining total utility over both material utility and gain-loss utility arising from the comparison of material utility to the reference point.
} 
with the narrow framing of individual gambles, while Read et al. (1999) survey the broader evidence on narrow framing.

Starting with Kahneman and Tversky (1979), most models of loss aversion take the reference point to be fixed exogenously, for example assuming it to be equal to the status quo. We noted above that the utility formulation (2) is flexible enough to incorporate loss aversion around a fixed reference point. Thus, an exogenous reference point does not introduce any interdependence between the efforts of the First and Second Movers (to see that Proposition 1 continues to hold, note that if $u_{2}\left(y_{2}\right)$ in (2) is redefined to include gain-loss utility, the analysis proceeds as before).

Instead of holding an exogenous reference point, we assume that a disappointment averse Second Mover is loss averse around an endogenous reference point equal to her expected material utility given the effort levels that are actually chosen, ${ }^{12}$ so

$$
R_{2}=E\left[u_{2}\left(y_{2}\right) \mid e_{2}, e_{1}\right]
$$

Thus a Second Mover's reference point will be sensitive to both the effort chosen by the First Mover and her own effort, and when optimizing the Second Mover understands that her effort choice affects her reference point. Notice that the endogeneity of the expectation is crucial. If the Second Mover starts with a reference point equal to a prior expectation which is invariant to the effort levels that are actually chosen, the reference point is fixed so, as explained above, Proposition 1 still holds. Instead, our reference point adjusts to the agents' choices: in the terminology of Köszegi and Rabin (2007) the reference point is choice-acclimating. ${ }^{13}$

To operationalize our model, we linearize material utility and gain-loss utility. ${ }^{14}$ We assume that $u_{2}\left(y_{2}\right)=y_{2}$, so material utility is linear in money and the Second Mover's reference point becomes her expected monetary payoff, i.e.,

$$
R_{2}=v P_{2}\left(e_{2}, e_{1}\right)
$$

Furthermore, we assume that the gain-loss utility arising from the comparison of $u_{2}\left(y_{2}\right)$ to the reference point is piece-wise linear, with a constant slope of $g_{2}$ in the gain domain and $l_{2}$ in the loss domain. With piece-wise linearity, loss aversion implies that $l_{2}>g_{2}$, so losses are more painful than same-sized gains are pleasurable. ${ }^{15}$ Thus we define disappointment aversion as follows.

\footnotetext{
${ }^{12}$ In a single agent set-up, Bell (1985) and Loomes and Sugden (1986) also use a reference point equal to expected material utility given the chosen action. Delquié and Cillo (2006a, 2006b) and Köszegi and Rabin (2006, 2007) argue that in a stochastic environment, the reference point itself should be taken to be a lottery, with an agent comparing the outcome to all the possible outcomes in the reference lottery and weighting each comparison by the probability of the relevant reference outcome. It is straightforward to show that in the linear environment considered below the reference lottery approach collapses to our single reference point set-up.

${ }^{13}$ Technically our game is psychological (Geanakoplos et al., 1989) as the Second Mover's utility depends on her beliefs about the chosen efforts via the reference point. In particular, our game falls under Battigalli and Dufwenberg (2009)'s framework of a dynamic psychological game as utility depends on terminal node (ex post) beliefs, which are pinned down by the chosen efforts, so beliefs can update during the course of the game. In Köszegi and Rabin (2006), by contrast, utilities depend only on initial beliefs as the reference point is given by a prior expectation which does not update in response to the chosen action (although an equilibrium consistency requirement is imposed on the expectation).

${ }^{14}$ Given the experimental stakes are small, we believe this comes at a low cost.

${ }^{15} \mathrm{With}$ piece-wise linearity, loss aversion and first-order loss aversion are equivalent. If $l_{2}=g_{2}$, gains and losses relative to the reference point cancel out in expectation, so the agent acts as if she had standard preferences.
} 
Definition 1 A disappointment averse Second Mover is loss averse around her expected monetary payoff, so $\lambda_{2} \equiv l_{2}-g_{2}$, which measures the strength of disappointment aversion, is strictly positive.

We can then express a disappointment averse Second Mover's expected utility as ${ }^{16}$

$$
\begin{aligned}
E U_{2}\left(e_{2}, e_{1}\right) & =P_{2}\left(v+g_{2}\left(v-v P_{2}\right)\right)+\left(1-P_{2}\right)\left(0+l_{2}\left(0-v P_{2}\right)\right)-C_{2}\left(e_{2}\right) \\
& =v P_{2}-\lambda_{2} v P_{2}\left(1-P_{2}\right)-C_{2}\left(e_{2}\right),
\end{aligned}
$$

and we let

$$
\Lambda_{2}\left(e_{2}-e_{1}\right) \equiv-\lambda_{2} v P_{2}\left(1-P_{2}\right)
$$

represent the extra term introduced into expected utility by disappointment aversion. (Recall from Section 3.2 that loss aversion around a fixed reference point, including one given by a prior expectation, or risk aversion in the absence of an endogenous reference point do not introduce a similar term.)

We call $\Lambda_{2}$ the Second Mover's disappointment deficit as it is always negative for $\lambda_{2}>0$ (strictly negative for $P_{i} \notin\{0,1\}$ ): a disappointment averse Second Mover dislikes variance in her monetary payoff as losses relative to her expected payoff loom larger than gains. (With risk aversion, agents care only about their probability of winning as there are only two possible outcomes.) The variance of the Second Mover's two-point distribution of monetary payoffs is given by $v P_{2}\left(1-P_{2}\right)$, which is strictly concave in $P_{2}$ and maximized at $P_{2}=\frac{1}{2}$, so given the linearity of $P_{2}$ in $e_{2}-e_{1}$ the disappointment deficit is strictly convex in the difference in efforts and at its most negative where the efforts are equal.

When efforts are such that the Second Mover has zero probability of winning, the Second Mover has a reference point of zero and her realized payoff equals her reference point; she is never disappointed and never receives more than expected. Hence her disappointment deficit is zero. Starting at zero, a small increase in her probability of winning leads to a large increase in the variance of her monetary payoff. Further increases in the probability of winning towards $\frac{1}{2}$ lead to further yet smaller increases in the variance. At $P_{2}=\frac{1}{2}$ the variance is at its highest so the disappointment deficit is at its most negative - irrespective of whether she wins or loses the Second Mover's realized payoff is very different from her expected payoff. Starting at $P_{2}=\frac{1}{2}$ increases in the probability of winning reduce the variance, initially by small amounts, and then by larger amounts as the probability of winning approaches 1 .

The convexity of the disappointment deficit is critical to understanding how the Second Mover responds to the First Mover's effort choice. For any value of the Second Mover's effort, an increase in the First Mover's effort reduces the Second Mover's probability of winning. This puts the Second Mover at a point on her disappointment deficit curve with a lower slope (less positive or more negative) so the Second Mover's effort has a smaller (again less positive or more negative) effect on the disappointment deficit, and hence the Second Mover has a lower

\footnotetext{
${ }^{16}$ In the context of desert preferences, whereby an agent's expectation represents how much she feels she deserves given how hard she was worked in comparison to her rival, Gill and Stone (2009) derive an equivalent formulation which they use to analyze simultaneous effort choices in a purely theoretical framework. Gill and Stone permit $g_{2}<0$ to model agents who feel guilty about doing better than deserved. All of our theoretical and empirical analysis continues to hold if we allow $g_{2}<0$ here.
} 
marginal incentive to exert effort. We thus have a discouragement effect, which is crucial to our identification strategy: a disappointment averse Second Mover responds negatively to the First Mover's effort, so the harder the First Mover works the more the Second Mover shies away from exerting effort. Thus First and Second Mover efforts are strategic substitutes. ${ }^{17}$

Proposition 2 When the Second Mover is disappointment averse, higher First Mover effort discourages the Second Mover: the Second Mover's optimal effort $e_{2}^{*}$ is always (weakly) decreasing in the First Mover's effort $e_{1}$.

Proof. See Appendix A.1.

Up to now we have imposed no assumptions on the shape of the cost of effort function. In order to derive an analytical expression for how the Second Mover responds to the First Mover's effort, and to see how the slope of the reaction function changes in the value of the prize and the strength of disappointment aversion, we now assume a quadratic cost of effort function:

$$
C_{2}\left(e_{2}\right)=b e_{2}+\frac{c e_{2}^{2}}{2}
$$

With this cost function, the Second Mover's objective function will be everywhere convex or everywhere concave. With strict convexity, the Second Mover will always set effort at a corner. Instead we focus here on the case of strict concavity, which allows interior optima, showing that the discouragement effect becomes stronger as the Second Mover becomes more disappointment averse or the value of the prize goes up.

Proposition 3 Suppose a disappointment averse Second Mover has a quadratic cost function (given by (9)) and a strictly concave objective function, i.e., $2 \gamma^{2} c-\lambda_{2} v>0$. When the action space is continuous, the slope of the Second Mover's reaction function in the interior is given by

$$
\frac{d e_{2}^{*}}{d e_{1}}=\frac{-\lambda_{2} v}{2 \gamma^{2} c-\lambda_{2} v}<0
$$

which becomes strictly more negative in the strength of disappointment aversion $\lambda_{2}$ and the value of the prize $v$. When the action space is discrete, the discrete analogue of the reaction function behaves similarly.

Proof. See Appendix A.2.

These effects are intuitive. Referring back to (8) we see that the disappointment deficit term becomes more negative in the strength of disappointment aversion $\lambda_{2}$ and the value of the prize $v$. The variance of the monetary payoff goes up in the size of the prize, and the stronger is disappointment aversion, the greater the weight put on this variance.

\footnotetext{
${ }^{17}$ It is straightforward to extend the proof of Proposition 2 to show that if $\lambda_{2}$ were negative, the Second Mover would respond positively to the First Mover's effort.
} 


\section{Empirical Analysis}

\subsection{Overview and Sample Description}

We use the data set collected from the laboratory experiment described in Section 2 to test our theory of disappointment aversion. In Section 4.2 we show in a reduced form setting that, as predicted by our theory of disappointment aversion, Second Movers respond negatively to the effort choice of the First Mover they are paired with and that the strength of this effect is increasing in the value of the prize. In Section 4.3 we use structural modeling to estimate the strength of disappointment aversion on average and the heterogeneity in disappointment aversion across the population. As outlined in the Introduction, our estimation strategies exploit identifying variation obtained from the properties of our slider task together with the experimental design. In Section 4.4 we discuss how our results provide evidence for endogenous choice-acclimating reference points and we relate our estimate of the disappointment aversion parameter to existing estimates of loss aversion.

We analyze the behavior of Second Movers conditional on the effort choices of the First Movers. This conditional analysis is sufficient for the purpose of identifying the presence and strength of disappointment aversion. Moreover, solving for the optimal behavior of the First Movers requires further assumptions concerning the First Movers' beliefs about the unobserved characteristics and behavior of the Second Movers. We avoid these issues, together with the associated computational complexities and potential sources of misspecification, when performing a conditional analysis of the Second Mover effort choices.

As noted in Section 2.1.1, we interpret the number of sliders correctly positioned within the allotted time, i.e., the points score, as the effort exerted by the subject. We comment here on two features of this effort measure. First, as explained in Section 2.1.2, the design of our slider task ensures that points scores correspond closely to effort exerted. Second, while the slider task provides a fine measure of effort, effort is still discrete. We emphasize that this discreteness is entirely unproblematic. Indeed, the above theoretical framework encompasses both discrete and continuous effort choices, and the testable implications of our theory of disappointment aversion apply irrespective of whether effort is discrete or continuous. In addition, as explained below, discrete effort choices are easily accommodated in our structural model.

From the laboratory sessions we collected data on 60 First Movers and 60 Second Movers, each observed for 10 paying rounds, with re-pairing between rounds as detailed in Section 2.2. One Second Mover appears to have been unable to position any sliders at exactly 50 and this subject is dropped from our preferred sample. ${ }^{18}$ However, we show that our results are robust to our sample selection. Table 1 summarizes the behavior of the 59 Second Movers and the corresponding First Movers in each round. Efforts range between 0 and 41 sliders for First Movers and 0 and 40 sliders for Second Movers. Within each round, on average First and Second Movers exert roughly the same effort, with average effort increasing from around 22 sliders to just under 27 sliders over the 10 rounds.

\footnotetext{
${ }^{18}$ The data show that this subject was moving sliders around throughout the session but failed to position any sliders at exactly 50 in either the practice rounds or in the paying rounds. This subject also experienced problems when entering his/her Participant ID number.
} 


\begin{tabular}{|c|c|c|c|c|c|c|c|c|}
\hline \multirow{2}{*}{$\begin{array}{l}\text { Paying } \\
\text { Round }\end{array}$} & \multirow{2}{*}{$\operatorname{Mean}\left(e_{1}\right)$} & \multirow{2}{*}{$\mathrm{SD}\left(e_{1}\right)$} & \multirow{2}{*}{$\operatorname{Mean}\left(e_{2}\right)$} & \multirow{2}{*}{$\mathrm{SD}\left(e_{2}\right)$} & \multicolumn{2}{|c|}{ Minimum } & \multicolumn{2}{|c|}{ Maximum } \\
\hline & & & & & $e_{1}$ & $e_{2}$ & $e_{1}$ & $e_{2}$ \\
\hline 1 & 22.034 & 5.991 & 21.763 & 6.101 & 1 & 0 & 33 & 34 \\
\hline 2 & 22.627 & 6.708 & 23.458 & 4.836 & 0 & 11 & 33 & 33 \\
\hline 3 & 24.763 & 6.075 & 24.831 & 4.875 & 0 & 12 & 37 & 38 \\
\hline 4 & 24.627 & 5.956 & 25.203 & 4.502 & 0 & 16 & 35 & 36 \\
\hline 5 & 24.966 & 6.800 & 25.119 & 5.660 & 0 & 0 & 36 & 35 \\
\hline 6 & 24.729 & 7.508 & 24.898 & 7.039 & 1 & 0 & 37 & 39 \\
\hline 7 & 25.881 & 5.855 & 25.763 & 6.109 & 9 & 0 & 37 & 37 \\
\hline 8 & 26.831 & 5.858 & 26.169 & 5.133 & 9 & 14 & 41 & 35 \\
\hline 9 & 25.593 & 8.550 & 26.254 & 6.702 & 0 & 0 & 38 & 40 \\
\hline 10 & 26.322 & 6.781 & 26.729 & 5.988 & 1 & 0 & 40 & 39 \\
\hline
\end{tabular}

Notes: SD denotes standard deviation and $e_{1}$ and $e_{2}$ denote, respectively, First and Second Mover effort.

Table 1: Summary of First and Second Mover efforts.

\subsection{Reduced Form Analysis}

We use a panel data regression to examine whether Second Movers respond to the effort choice of the First Mover they are paired with. Exploiting Proposition 1, we hypothesize that if Second Movers are not disappointment averse then the observed efforts of the Second Movers will not depend on the corresponding First Mover efforts once controls for the prize and round effects are included. ${ }^{19}$ Alternatively, if subjects are disappointment averse then Proposition 2 implies a negative dependence of observed Second Mover efforts on the corresponding First Mover efforts, again conditional on controls for the prize and round effects.

To explore how Second Movers respond to First Mover effort we estimate the following linear random effects panel data model:

$$
e_{2, n, r}=\beta_{1}+\beta_{2} v_{n, r}+\beta_{3} e_{1, n, r}+\beta_{4} e_{1, n, r} \times v_{n, r}+d_{r}+\omega_{n}+\epsilon_{n, r} \text { for } n=1, \ldots, N ; r=1, \ldots, 10
$$

where $n$ and $r$ index, respectively, Second Movers and paying rounds, and $N$ denotes the total number of Second Movers. $e_{1, n, r}$ is the effort of the First Mover paired with the $n^{\text {th }}$ Second Mover in the $r^{\text {th }}$ round, and $v_{n, r}$ is the prize draw for the $n^{\text {th }}$ Second Mover in the $r^{\text {th }}$ round. The prize, the First Mover's effort and the First Mover's effort interacted with the prize are included as explanatory variables. The inclusion of the interaction of the prize and the First Mover's effort is motivated by Proposition 3 which shows that in the case of a quadratic cost of effort function the negative effect of the First Mover's effort on the Second Mover's optimal effort is larger at higher prizes. Additionally, the equation includes a set of round dummies denoted by $d_{r}$ for $r=1, \ldots, 10$, with the first paying round providing the omitted category, to capture systematic differences between rounds which are common across Second Movers, and round invariant Second Mover specific effects denoted $\omega_{n}$ for $n=1, \ldots, N$ to capture systematic

\footnotetext{
${ }^{19}$ We note however that First and Second Mover efforts will not be unconditionally independent in the presence of prize and round effects which impact on both pair members.
} 
differences between Second Movers. Lastly, $\epsilon_{n, r}$ is an unobservable that varies over rounds and over Second Movers and captures differences between rounds in a Second Mover's effort choice that cannot be attributed to the other terms in the model. $\omega_{n}$ is assumed to be identically and independently distributed over Second Movers with a variance $\sigma_{\omega}^{2}$, while $\epsilon_{n, r}$ is assumed to be identically and independently distributed over rounds and Second Movers with a variance $\sigma_{\epsilon}^{2}$.

\begin{tabular}{|c|c|c|c|c|}
\hline & \multirow{2}{*}{\multicolumn{2}{|c|}{$\begin{array}{l}\text { Preferred Sample } \\
59 \text { Second Movers }\end{array}$}} & \multirow{2}{*}{\multicolumn{2}{|c|}{$\begin{array}{c}\text { Full Sample } \\
60 \text { Second Movers }\end{array}$}} \\
\hline & & & & \\
\hline & Coefficient & $\begin{array}{l}\mathrm{z} \text { value } \\
\text { ( } \mathrm{p} \text { value) }\end{array}$ & Coefficient & $\begin{array}{l}\text { Z value } \\
\text { (p value) }\end{array}$ \\
\hline First Mover effort & 0.044 & $\begin{array}{l}0.898 \\
(0.369)\end{array}$ & 0.047 & $\begin{array}{l}0.963 \\
(0.336)\end{array}$ \\
\hline Prize & $1.639^{* * *}$ & $\begin{array}{l}2.724 \\
(0.006)\end{array}$ & $1.655^{* * *}$ & $\begin{array}{l}2.794 \\
(0.005)\end{array}$ \\
\hline Prize $\times$ First Mover effort & $-0.049^{* *}$ & $\begin{array}{r}-2.083 \\
(0.037)\end{array}$ & $-0.050^{* *}$ & $\begin{array}{r}-2.179 \\
(0.029)\end{array}$ \\
\hline$d_{2}$ & $1.689^{* *}$ & $\begin{array}{l}2.381 \\
(0.017)\end{array}$ & $1.655^{* *}$ & $\begin{array}{l}2.368 \\
(0.018)\end{array}$ \\
\hline$d_{3}$ & $3.084^{* * *}$ & $\begin{array}{l}4.325 \\
(0.000)\end{array}$ & $3.034^{* * *}$ & $\begin{array}{l}4.323 \\
(0.000)\end{array}$ \\
\hline$d_{4}$ & $3.448^{* * *}$ & $\begin{array}{l}4.838 \\
(0.000)\end{array}$ & $3.369^{* * *}$ & $\begin{array}{l}4.801 \\
(0.000)\end{array}$ \\
\hline$d_{5}$ & $3.322^{* * *}$ & $\begin{array}{l}4.650 \\
(0.000)\end{array}$ & $3.279^{* * *}$ & $\begin{array}{l}4.661 \\
(0.000)\end{array}$ \\
\hline$d_{6}$ & $3.262^{* * *}$ & $\begin{array}{l}4.577 \\
(0.000)\end{array}$ & $3.193^{* * *}$ & $\begin{array}{l}4.554 \\
(0.000)\end{array}$ \\
\hline$d_{7}$ & $4.123^{* * *}$ & $\begin{array}{l}5.756 \\
(0.000)\end{array}$ & $4.043^{* * *}$ & $\begin{array}{l}5.734 \\
(0.000)\end{array}$ \\
\hline$d_{8}$ & $4.567^{* * *}$ & $\begin{array}{l}6.341 \\
(0.000)\end{array}$ & $4.487^{* * *}$ & $\begin{array}{l}6.330 \\
(0.000)\end{array}$ \\
\hline$d_{9}$ & $4.709^{* * *}$ & $\begin{array}{l}6.582 \\
(0.000)\end{array}$ & $4.632^{* * *}$ & $\begin{array}{l}6.579 \\
(0.000)\end{array}$ \\
\hline$d_{10}$ & $5.180^{* * *}$ & $\begin{array}{l}7.148 \\
(0.000)\end{array}$ & $5.066^{* * *}$ & $\begin{array}{l}7.115 \\
(0.000)\end{array}$ \\
\hline Intercept & $19.777^{* * *}$ & $\begin{array}{r}14.126 \\
(0.000) \\
\end{array}$ & $19.392^{* * *}$ & $\begin{array}{r}13.400 \\
(0.000)\end{array}$ \\
\hline$\sigma_{\omega}$ & \multicolumn{2}{|c|}{4.288} & \multicolumn{2}{|c|}{5.342} \\
\hline$\sigma_{\epsilon}$ & \multicolumn{2}{|c|}{3.852} & \multicolumn{2}{|c|}{3.826} \\
\hline$N \times R$ & \multicolumn{2}{|c|}{590} & \multicolumn{2}{|c|}{600} \\
\hline$\chi^{2}$ test for no significant & \multicolumn{2}{|c|}{4.16} & \multicolumn{2}{|c|}{2.94} \\
\hline difference between men and women & \multicolumn{2}{|c|}{$d f=3, p=0.242$} & \multicolumn{2}{|c|}{$d f=3, p=0.235$} \\
\hline Hausman test for random & \multicolumn{2}{|c|}{2.43} & \multicolumn{2}{|c|}{2.43} \\
\hline versus fixed effects & \multicolumn{2}{|c|}{$d f=12, p=0.998$} & \multicolumn{2}{|c|}{$d f=12, p=0.998$} \\
\hline
\end{tabular}

Notes: ${ }^{*},{ }^{* *}$ and ${ }^{* * *}$ denote significance at the $10 \%, 5 \%$ and $1 \%$ levels. $d f$ denotes degrees of freedom.

Table 2: Random effects regressions for Second Mover effort.

Table 2 reports estimates of the parameters appearing in (11). The results for the preferred sample show a negative effect of First Mover effort on Second Mover effort. In more detail, at low prizes First Mover effort does not significantly affect Second Mover effort, while at high prizes there is a large and significant discouragement effect as predicted by our theory of disappointment aversion. Application of the Delta method reveals that the effect of First Mover effort on Second Mover effort is not significant at the $5 \%$ level for prizes less than $£ 2$, is significant at the $5 \%$ level 
for prizes between $£ 2$ and $£ 2.60$, and is significant at the $1 \%$ level for prizes of $£ 2.70$ and above. For the highest prize of $£ 3.90$ a 10 slider increase in First Mover effort decreases Second Mover effort by approximately 1.5 sliders. Furthermore, there are large and significant positive prize effects, and we find that the persistent unobserved individual characteristics explain more of the variation in behavior than the transitory unobservables. The round dummies reveal significant increases in effort over the 10 rounds which we interpret as a reduction in the marginal cost of effort due to learning-by-doing.

Additional regressions, not reported, allow the coefficients on First Mover effort, the prize and the interaction of these two variables to differ between men and women. No significant gender differences were found. This suggests that Niederle and Vesterlund (2007)'s finding that men have a stronger preference for competition compared to women cannot be explained by differential levels of disappointment aversion across gender when agents compete.

We note that, although the parameters reported in Table 2 were estimated from a linear random effects model, an alternative specification in which round invariant Second Mover specific effects are treated as fixed effects yields almost indistinguishable results. This is because Second Mover specific effects are uncorrelated with the prize and the First Mover efforts due to the experimental design. Finally, Table 2 shows that including the $60^{\text {th }}$ Second Mover does not change conclusions concerning significance, and nor does this have substantial effects on the coefficient estimates.

\subsection{Structural Modeling}

Structural modeling seeks to fit the theoretical model with disappointment aversion presented above in Section 3.3 to the experimental sample. In contrast to the reduced form analysis above, structural modeling recovers estimates of the strength of disappointment aversion on average and the population-level heterogeneity in disappointment aversion. Below we describe the empirical specification, the estimation strategy, including a discussion of identification, and the results.

\subsubsection{Empirical Specification}

We use $\lambda_{2, n}$ to denote the disappointment aversion parameter of the $n^{\text {th }}$ Second Mover. In this specification the strength of disappointment aversion may vary between subjects; however, for a given subject the strength of disappointment is constant over rounds. We adopt the following specification for $\lambda_{2, n}$ :

$$
\lambda_{2, n} \sim N\left(\widetilde{\lambda}_{2}, \sigma_{\lambda}^{2}\right) \text { for } n=1, \ldots, N,
$$

and further assume that $\lambda_{2, n}$ is independent over Second Movers. The parameter $\widetilde{\lambda}_{2}$ represents the strength of disappointment aversion on average, and $\sigma_{\lambda}^{2}$ denotes the variance of the strength of disappointment aversion in the population.

The cost of effort function is assumed to be quadratic, as in (9). The parameter $b$ is assumed to be constant over rounds and common to Second Movers, while unobserved cost differences between Second Movers and learning effects enter the cost of effort function through the convexity parameter $c . c_{n, r}$ denotes the convexity parameter of the $n^{\text {th }}$ Second Mover in the $r^{\text {th }}$ 
round and takes the following form:

$$
c_{n, r}=\kappa+\delta_{r}+\mu_{n}+\pi_{n, r} \text { for } n=1, \ldots, N ; r=1, \ldots, 10 .
$$

In the above $\kappa$ denotes the component of $c_{n, r}$ which is common across Second Movers and rounds. $\delta_{r}$ for $r=1, \ldots, 10$ are round effects, with the first paying round providing the omitted category. A cost of effort that is declining over rounds due to learning is therefore represented by values of $\delta_{r}$ which are negative and decreasing over rounds. $\mu_{n}$ denotes unobserved differences in the cost of effort functions across Second Movers that are constant over rounds. For the purpose of estimation $\mu_{n}$ is assumed to be independent over Second Movers and to have a Weibull distribution with scale parameter $\phi_{\mu}$ and shape parameter $\varphi_{\mu}$. The final term in the cost function is $\pi_{n, r}$ which represents unobserved differences in Second Movers' cost of effort functions that vary over rounds as well as over Second Movers. $\pi_{n, r}$ is assumed to be independent over Second Movers and rounds and to have a Weibull distribution with scale parameter $\phi_{\pi}$ and shape parameter $\varphi_{\pi}$. The Weibull distribution is a flexible two parameter distribution that has positive support, thus allowing us to impose convex cost of effort functions on all Second Movers when estimating the model. ${ }^{20}$

Given this parameterization of the theoretical model, the structural model has 17 unknown parameters, corresponding to the parameters describing disappointment aversion, $\widetilde{\lambda}_{2}$ and $\sigma_{\lambda}$, the common cost parameters $b$ and $\kappa$, the 9 round effects $\delta_{r}$ for $r=2, \ldots, 10$ and the 4 parameters appearing in the distribution of the unobservables in the cost of effort function, namely, $\phi_{\mu}, \varphi_{\mu}$, $\phi_{\pi}$ and $\varphi_{\pi}$. These 17 structural parameters are collectively denoted by the vector $\theta$.

\subsubsection{Estimation Strategy and Identification}

We estimate the 17 unknown parameters using the Method of Simulated Moments (MSM) (McFadden, 1989; Pakes and Pollard, 1989). The analytic complexity of choice probabilities, due to the multiple sources of unobserved heterogeneity, precludes the use of Maximum Likelihood and Method of Moments estimation techniques. MSM, in contrast, uses easily computed features of the sample as the basis for estimating the unknown parameters. Formally, the sample observations are used to compute a $k \times 1$ dimensional vector of moments, with $k \geq 17$, denoted $M$. Critically, every moment included in $M$ should depend at least in part on one or more endogenous variables. The researcher has considerable discretion over the moments included in $M$; however $M$ typically includes period specific averages of endogenous variables, here the effort choices of the Second Movers in each round, together with correlations between the endogenous variables and the explanatory variables.

MSM proceeds by generating $S$ simulated samples. Each simulated sample contains $N$ Second Movers each observed for 10 rounds. In each simulated sample the Second Movers face the same prizes and First Mover efforts as observed in the actual sample. The behavior of the Second Movers in the simulated samples is determined from the structural model using a trial value, $\theta_{t}$, of the values of the unknown parameters, $\theta$. In particular, unobservables are assigned to Second Movers in accordance with the above described distributions. For each Second Mover

\footnotetext{
${ }^{20}$ In Section 4.3.3 we show that replacing the Weibull distribution with the normal distribution reduces the model's goodness of fit.
} 
and each round, the expected utility is calculated for each feasible Second Mover effort choice, and the simulated effort choice is the action with the highest expected utility. Further details concerning the construction of the simulated samples are provided in Appendix B.1.

The behavior of the Second Movers in the simulated samples is then compared to the behavior of the actual experimental subjects. Specifically, for each of the $S$ simulated samples the vector of moments $M_{s}\left(\theta_{t}\right)$ is computed. These are the same $k$ moments as computed for the observed sample. The simulated moments $M_{s}$ are a function of the parameters $\theta_{t}$ used to simulate the behavior of the Second Movers as different values of the parameters imply different optimal Second Mover effort choices. The average of $M_{s}$ over the $S$ simulated samples, $\frac{1}{S} \sum_{s=1}^{S} M_{s}\left(\theta_{t}\right)$, provides a summary of the behavior of Second Movers in the simulated samples. The process of averaging over the $S$ simulated samples reduces the effect of simulation noise on the simulated moments. The following metric is then formed:

$$
J\left(\theta_{t}\right)=\left(M-\frac{1}{S} \sum_{s=1}^{S} M_{s}\left(\theta_{t}\right)\right)^{\prime} W_{N}\left(M-\frac{1}{S} \sum_{s=1}^{S} M_{s}\left(\theta_{t}\right)\right),
$$

where $W_{N}$ is a fixed $k \times k$ dimensional positive semidefinite weighting matrix. The quantity $J\left(\theta_{t}\right)$ provides a scalar measure of the distance between the observed behavior of the actual experimental subjects and the behavior of the Second Movers in the simulated samples at the trial parameter vector $\theta_{t}$. The MSM estimator of $\theta$, denoted $\widehat{\theta}$, is the value of $\theta_{t}$ that minimizes $J\left(\theta_{t}\right): \widehat{\theta}=\operatorname{argmin}_{\theta_{t}} J\left(\theta_{t}\right)$. Thus MSM estimates the structural parameters to be such that the behavior of Second Movers simulated on the basis of the structural model is as similar as possible to the behavior of the actual Second Movers as observed in sample.

Under the conditions of Pakes and Pollard (1989), the MSM estimator is consistent and asymptotically normal for any consistent weight matrix $W_{N}$. We use bootstrap sampling of Second Movers with replacement to estimate $W_{N}$. Efficiency is maximized by setting $W_{N}$ to be the inverse of $N$ times the covariance matrix of the sample moments, which yields an Optimally Weighted Minimum Distance estimator (OWMD). However, it is well known that this choice of $W_{N}$ can introduce finite sample bias (see for example Altonji and Segal, 1996). Thus our preferred estimator uses a weight matrix with diagonal elements equal to the inverse of $N$ times the variances of the sample moments and zeros elsewhere, which yields a Diagonally Weighted Minimum Distance estimator (DWMD). Further details pertaining to the properties of the MSM estimator and estimation routine are presented in Appendix B.2.

We use 38 moments to estimate the 17 structural parameters. The moments are described in Table 4 in Appendix B.3. Correlations between Second Mover effort and First Mover effort and between Second Mover effort and First Mover effort interacted with the prize provide identifying information about $\widetilde{\lambda}_{2}$, the parameter describing the strength of disappointment aversion on average. Percentiles of Second Mover specific correlations provide information about the standard deviation of disappointment aversion in the population, $\sigma_{\lambda}$. The correlation between Second Mover effort and the prize helps to identify $\kappa$, which measures the component of the convexity of the cost of effort function common to Second Movers and rounds, while the associated percentiles help to identify the shape of the distributions of the unobserved cost differences between Second Movers. Moments pertaining to the marginal distribution of Second Mover effort, such 
as round specific means and the standard deviation, provide further identifying information.

\subsubsection{Results}

\begin{tabular}{|c|c|c|c|c|}
\hline & \multirow{2}{*}{$\frac{\text { Preferred Spec. }}{\text { DWMD }}$} & \multicolumn{3}{|c|}{ Robustness Checks } \\
\hline & & OWMD & DWMD & DWMD \\
\hline & 59 Second Movers & 59 Second Movers & 59 Second Movers & 60 Second Movers \\
\hline & Weibull Costs & Weibull Costs & Normal Costs & Weibull Costs \\
\hline$\widetilde{\lambda}_{2}$ & $\begin{array}{c}1.724 \\
(0.479)[0.000]\end{array}$ & $\begin{array}{c}1.497 \\
(0.258)[0.000]\end{array}$ & $\begin{array}{c}1.199 \\
(0.347)[0.001]\end{array}$ & $\begin{array}{c}1.409 \\
(0.323)[0.000]\end{array}$ \\
\hline$\sigma_{\lambda}$ & $\begin{array}{c}1.433 \\
(0.492)[0.004]\end{array}$ & $\begin{array}{c}1.153 \\
(0.154)[0.000]\end{array}$ & $\begin{array}{c}1.298 \\
(0.308)[0.000]\end{array}$ & $\begin{array}{c}1.508 \\
(0.455)[0.001]\end{array}$ \\
\hline$b$ & $\begin{array}{l}-0.532 \\
(0.033)[0.000]\end{array}$ & $\begin{array}{l}-0.566 \\
(0.013)[0.000]\end{array}$ & $\begin{array}{l}-0.522 \\
(0.017)[0.000]\end{array}$ & $\begin{array}{l}-0.506 \\
(0.017)[0.000]\end{array}$ \\
\hline$\kappa$ & $\begin{array}{c}1.868 \\
(0.095)[0.000]\end{array}$ & $\begin{array}{c}2.069 \\
(0.037)[0.000]\end{array}$ & $\begin{array}{c}2.568 \\
(0.053)[0.000]\end{array}$ & $\begin{array}{c}1.808 \\
(0.074)[0.000]\end{array}$ \\
\hline$\delta_{2}$ & $\begin{array}{l}-0.162 \\
(0.043)[0.000]\end{array}$ & $\begin{array}{c}-0.198 \\
(0.033)[0.000]\end{array}$ & $\begin{array}{l}-0.163 \\
(0.034)[0.000]\end{array}$ & $\begin{array}{c}-0.171 \\
(0.056)[0.000]\end{array}$ \\
\hline$\delta_{3}$ & $\begin{array}{c}-0.265 \\
(0.040)[0.000]\end{array}$ & $\begin{array}{c}-0.313 \\
(0.030)[0.000]\end{array}$ & $\begin{array}{c}-0.321 \\
(0.050)[0.000]\end{array}$ & $\begin{array}{c}-0.301 \\
(0.059)[0.000]\end{array}$ \\
\hline$\delta_{4}$ & $\begin{array}{l}-0.314 \\
(0.051)[0.000]\end{array}$ & $\begin{array}{c}-0.332 \\
(0.032)[0.000]\end{array}$ & $\begin{array}{l}-0.344 \\
(0.031)[0.000]\end{array}$ & $\begin{array}{l}-0.306 \\
(0.074)[0.000]\end{array}$ \\
\hline$\delta_{5}$ & $\begin{array}{c}-0.315 \\
(0.040)[0.000]\end{array}$ & $\begin{array}{c}-0.394 \\
(0.032)[0.000]\end{array}$ & $\begin{array}{l}-0.341 \\
(0.063)[0.000]\end{array}$ & $\begin{array}{c}-0.285 \\
(0.072)[0.000]\end{array}$ \\
\hline$\delta_{6}$ & $\begin{array}{c}-0.290 \\
(0.050)[0.000]\end{array}$ & $\begin{array}{c}-0.379 \\
(0.040)[0.000]\end{array}$ & $\begin{array}{c}-0.315 \\
(0.054)[0.000]\end{array}$ & $\begin{array}{c}-0.276 \\
(0.076)[0.000]\end{array}$ \\
\hline$\delta_{7}$ & $\begin{array}{c}-0.363 \\
(0.049)[0.000]\end{array}$ & $\begin{array}{c}-0.444 \\
(0.031)[0.000]\end{array}$ & $\begin{array}{c}-0.394 \\
(0.048)[0.000]\end{array}$ & $\begin{array}{c}-0.352 \\
(0.067)[0.000]\end{array}$ \\
\hline$\delta_{8}$ & $\begin{array}{l}-0.411 \\
(0.046)[0.000]\end{array}$ & $\begin{array}{c}-0.431 \\
(0.029)[0.000]\end{array}$ & $\begin{array}{l}-0.431 \\
(0.043)[0.000]\end{array}$ & $\begin{array}{c}-0.413 \\
(0.063)[0.000]\end{array}$ \\
\hline$\delta_{9}$ & $\begin{array}{c}-0.390 \\
(0.063)[0.000]\end{array}$ & $\begin{array}{l}-0.465 \\
(0.039)[0.000]\end{array}$ & $\begin{array}{c}-0.436 \\
(0.052)[0.000]\end{array}$ & $\begin{array}{c}-0.379 \\
(0.063)[0.000]\end{array}$ \\
\hline$\delta_{10}$ & $\begin{array}{l}-0.449 \\
(0.046)[0.000]\end{array}$ & $\begin{array}{c}-0.548 \\
(0.028)[0.000]\end{array}$ & $\begin{array}{c}-0.493 \\
(0.035)[0.000]\end{array}$ & $\begin{array}{c}-0.435 \\
(0.058)[0.000]\end{array}$ \\
\hline$\phi_{\pi}$ & $\begin{array}{c}0.322 \\
(0.064)[0.000]\end{array}$ & $\begin{array}{c}0.164 \\
(0.015)[0.000]\end{array}$ & - & $\begin{array}{c}0.211 \\
(0.048)[0.000]\end{array}$ \\
\hline$\phi_{\mu}$ & $\begin{array}{c}0.436 \\
(0.035)[0.000]\end{array}$ & $\begin{array}{c}0.529 \\
(0.036)[0.000]\end{array}$ & - & $\begin{array}{c}0.504 \\
(0.058)[0.000]\end{array}$ \\
\hline$\varphi_{\pi}$ & $\begin{array}{c}1.016 \\
(0.118)[0.000]\end{array}$ & $\begin{array}{c}0.660 \\
(0.034)[0.000]\end{array}$ & - & $\begin{array}{c}0.809 \\
(0.069)[0.000]\end{array}$ \\
\hline$\varphi_{\mu}$ & $\begin{array}{c}0.918 \\
(0.086)[0.000]\end{array}$ & $\begin{array}{c}1.163 \\
(0.031)[0.000]\end{array}$ & - & $\begin{array}{c}0.948 \\
(0.082)[0.000]\end{array}$ \\
\hline$\sigma_{\pi}$ & $\begin{array}{c}0.320 \\
(0.050)[0.000]\end{array}$ & $\begin{array}{c}0.356 \\
(0.034)[0.000]\end{array}$ & $\begin{array}{c}0.207 \\
(0.021)[0.000]\end{array}$ & $\begin{array}{c}0.307 \\
(0.067)[0.000]\end{array}$ \\
\hline$\sigma_{\mu}$ & $\begin{array}{c}0.493 \\
(0.048)[0.000] \\
\end{array}$ & $\begin{array}{c}0.432 \\
(0.032)[0.000] \\
\end{array}$ & $\begin{array}{c}0.290 \\
(0.019)[0.000] \\
\end{array}$ & $\begin{array}{c}0.552 \\
(0.108)[0.000] \\
\end{array}$ \\
\hline
\end{tabular}

Notes: Standard errors in parentheses and $\mathrm{p}$ values in brackets. Standard deviations of the transitory and persistent unobservables in the cost of effort function, $\sigma_{\pi}$ and $\sigma_{\mu}$, are estimated directly in the specification using normally distributed unobservables and computed from the other parameters for the specifications using the Weibull distribution. Estimates of $\kappa, \delta_{r}$ for $r=2, \ldots 10, \phi_{\pi}$ and $\phi_{\mu}$ have been multiplied by 100 .

Table 3: MSM parameter estimates. 
The first column of Table 3 reports the parameter estimates for the preferred specification, which is based on the sample of 59 Second Movers, assumes Weibull distributed unobservables in the cost of effort function and relies on a diagonal weight matrix. Before discussing the results we briefly consider the goodness of fit of this specification represented by the relevant moments in Table 5 located in Appendix B.3. Table 5 shows that for this specification all simulated moments correspond closely to the values observed in the sample: in particular the observed and simulated moments never differ by more than 1.3 bootstrapped standard deviations.

Turning to the parameter estimates for the preferred specification in the first column of Table 3, our estimate of the strength of disappointment aversion on average, $\widetilde{\lambda}_{2}$, is 1.724 and this is significantly different from zero at all conventional significance levels. In Section 4.4.2 we place this estimate in the context of the related literature but we note here that a figure of 1.724 is in line with previous studies which estimate the strength of loss aversion around a fixed reference point. We find that $\sigma_{\lambda}$ is significantly greater than zero, thus providing evidence for heterogeneity in disappointment aversion across individuals. Our parameter estimates imply that $\lambda_{2, n}$ is greater than 2.9 for $20 \%$ of individuals, and is less than 0.5 for $20 \%$. For $11 \%$ of individuals, $\lambda_{2, n}$ is less than zero.

The results further show that the cost of effort function exhibits significant convexity, and learning effects work to reduce the convexity of the cost of effort over rounds, leading to higher average effort levels in later rounds. In addition there is significant transitory and permanent variation over Second Movers in the cost of effort, with persistent unobserved differences being more important than transitory differences. Our estimate of $b$, the linear component of the cost of effort function, is negative, indicating that the cost of effort is declining at low effort levels. This negative coefficient is required to fit accurately observed average Second Mover effort. However, the linear component of the cost of effort function does not affect how Second Movers respond to the First Movers' efforts. Moreover, it is not surprising that the cost of effort is at first declining as the experimental subjects have self-selected into participating in the experiment and the outside option during the task is to do nothing for 120 seconds. Other experiments have also found that subjects derive some utility from carrying out real effort tasks, e.g., Brüggen and Strobel (2007).

Next we explore how the disappointment aversion impacts on the effort choices of the Second Movers and in particular look at how Second Movers responds to First Mover effort. Figure 3(a) shows the mean best response of Second Movers with the average value of $\lambda_{2, n}$ to the effort choice of the First Mover. ${ }^{21}$ We see strong negative effects of First Mover effort on Second Mover effort at prizes of $£ 2$ and $£ 3.90$ and essentially no effect at the lowest prize of $£ 0.10$. Standard errors, not reported, show that the slope of the reaction function is significantly neg-

\footnotetext{
${ }^{21}$ Reaction functions were obtained using simulation methods. Specifically, we consider a large number of hypothetical Second Movers, and for each hypothetical Second Mover made draws from the estimated distributions of $\mu_{n}$ and $\pi_{n, r}$ for the preferred specification. Using the estimated parameters of the cost of effort function for round 5, we simulated each hypothetical Second Mover's optimal effort conditional on specific values of First Mover effort and the prize, and computed the mean best response. Reaction functions were obtained by repeating this exercise while varying First Mover effort but holding the prize fixed. Reaction functions are linear and this is a consequence of the quadratic cost of effort function.
} 
ative (at the $1 \%$ level) at prizes of $£ 2$ and $£ 3.90 .^{22}$ Figure $3(\mathrm{~b})$ meanwhile shows the extent to which heterogeneity in disappointment aversion translates into differences in mean Second Mover responses to First Mover effort, evaluated at the average prize of $£ 2$. Second Movers with low values of $\lambda_{2, n}$, defined to be the $20^{\text {th }}$ percentile of the distribution of $\lambda_{2, n}$, do not respond appreciably to changes in First Mover effort. In contrast, a discouragement effect is observed for Second Movers with high values of $\lambda_{2, n}$, defined to be the $80^{\text {th }}$ percentile of the distribution of $\lambda_{2, n}$. Standard errors, not reported, show that the slope of the reaction function is significantly negative (at the $1 \%$ level) for Second Movers with high values of $\lambda_{2, n}$.

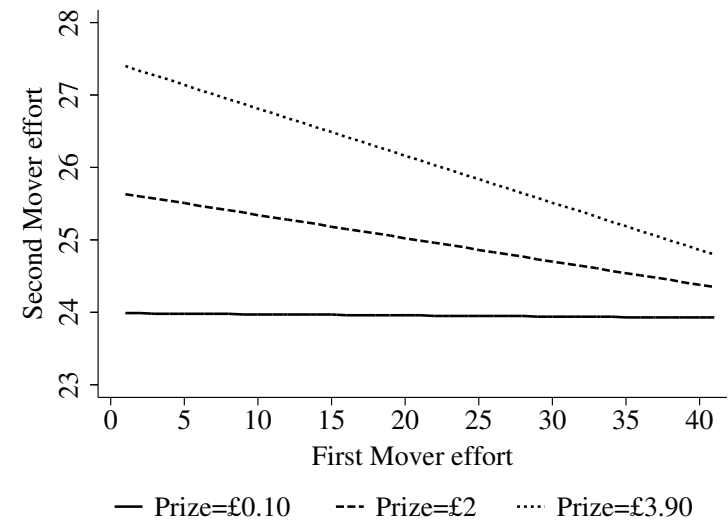

(a) Average lambda.

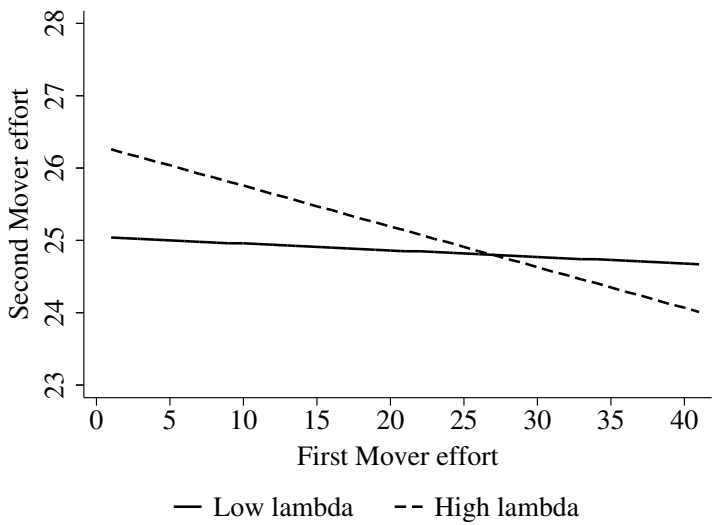

(b) Prize $=£ 2$.

Figure 3: Reaction functions implied by the preferred specification of the structural model.

Columns 2-4 of Table 3 provide robustness checks for various features of our analysis. We see that irrespective of the choice of sample, the method of weighting the moments and the distributional assumptions imposed on the cost of effort function, our estimate of the strength of disappointment aversion on average $\widetilde{\lambda}_{2}$ is significantly different from zero. Also, all specifications show significant variation across individuals in the strength of disappointment aversion. The OWMD and DWMD estimators give similar parameter estimates: thus there is little evidence that using the optimal weight matrix introduces finite sample bias. However we err on the side of caution and do not nominate this as our preferred specification. We also estimate a specification in which the unobservables appearing in the cost of effort function are normally distributed, rather than being drawn from Weibull distributions. While reducing by 2 the number of unknown parameters, the normal distribution is more restrictive than the Weibull, and leads to concave cost of effort functions for subjects with low cost draws. ${ }^{23}$ Table 5 shows that using the DWMD estimator with normally distributed unobservables in the cost of effort function fits less well than the preferred specification: the individual moments reveal that the deterioration in fit occurs as this specification does not fit as accurately the distribution of Second Mover efforts. Specifically, the standard deviations of observed and simulated Second Mover efforts differ by

\footnotetext{
${ }^{22}$ The magnitudes of the estimated slopes are lower than the corresponding estimates implied by the reduced form analysis in Section 4.2. This is because MSM seeks to fit simultaneously a variety of different moments. If we arbitrarily put a higher weight on the moments identifying these slopes, the estimated magnitudes would be larger.

${ }^{23}$ When estimating the specification with normally distributed unobservables in the cost of effort function we replace $c_{n, r}$ with $\max \left\{c_{n, r}, 0.0001\right\}$.
} 
2.3 bootstrapped standard deviations, while the proportions of very low and very high simulated Second Mover efforts are, respectively, 2.8 and 1.8 bootstrapped standard deviations different from the corresponding proportions observed in the sample. Increasing the sample size to 60 Second Movers also leads to a larger discrepancy between the standard deviations of observed and simulated Second Mover efforts than that obtained from the preferred specification.

\subsection{Endogenous Reference Points}

\subsubsection{Evidence}

Given that we model disappointment aversion as loss aversion around an agent's endogenous expectation, our finding of significant disappointment aversion provides evidence of loss aversion around choice-acclimating reference points when agents compete. With a fixed reference point, including one given by a prior expectation, Proposition 1 shows that we should observe no discouragement effect, and no disappointment deficit term appears in the expression for expected utility.

Thus our results speak to the debate about the speed at which reference points adjust. Köszegi and Rabin (2007) note that it is unclear how much time is needed between agents making their choices and the outcome occurring for the reference point to become choice-acclimating. Given the tiny temporal gap between the agents' effort choices and the outcome of the tournament, our results indicate that, at least in our competitive framework, the adjustment process is essentially instantaneous.

\subsubsection{Relationship to Existing Estimates of Loss Aversion}

The endogeneity of the reference point means that behavior in our model is driven by the size of the kink in gain-loss utility $\lambda_{2}=l_{2}-g_{2}$. Other models of choice-acclimating reference points share the same feature. To see this, we introduce Köszegi and Rabin (2006, 2007)'s parameterization, which involves a weighting on gain-loss utility relative to material utility, $\eta \geq 0$, and a coefficient of loss aversion for gain-loss utility, $\lambda$, which measures the ratio of the slopes of gain-loss utility alone in the loss and gain domains. We estimate the size of the kink in gain-loss utility, scaled relative to material utility, and $\lambda_{2}=\eta \lambda-\eta=\eta(\lambda-1)$. In their model of single-agent effort provision, Abeler et al. (2009)'s first-order conditions also depend on $\eta(\lambda-1)$, as do preferences over lotteries in the choice-acclimating version of Köszegi and Rabin (2007)'s model (see p. 1059 and Proposition 12(i)). Bell (1985)'s original disappointment aversion model also builds on the size of the kink. We cannot estimate $\lambda$ directly, as this coefficient interacts with the weight put on gain-loss utility to determine the size of the kink in gain-loss utility; nonetheless, because we estimate that $\widetilde{\lambda}_{2}>0$, it follows that $\eta>0$ and $\lambda>1 .^{24}$

Our measure of disappointment aversion is therefore not directly comparable to previous measures of loss aversion around fixed reference points. Evidence from previous studies suggests a coefficient of loss aversion of about 2 for Kahneman and Tversky (1979)'s value function (Kahneman, 2003), i.e., the value function is about twice as steep in the loss domain as it is in the gain domain. For example, from choices over lotteries Tversky and Kahneman (1992)

\footnotetext{
${ }^{24}$ Even though their reference point is fixed at the point of optimization, Crawford and Meng (2009) are also unable to separately identify $\lambda$ and $\eta$.
} 
estimate a coefficient of 2.25 for their median subject. Kahneman and Tversky (1979)'s value function is defined only over gains and losses: if we consider this value function to include implicitly any consumption value of losses and gains as well as psychological elation and pain from deviating from the reference point, then the comparable figure in our setting to the usual loss aversion coefficient is the ratio of the slopes of total utility in the loss and gain domains, given by

$$
\frac{1+l_{2}}{1+g_{2}}=1+\frac{\lambda_{2}}{1+g_{2}}
$$

Given an assumption about $g_{2}$, our estimate of $\tilde{\lambda}_{2}$ therefore implies an estimate of the average value of $(15)$ in the population. For example, if we assume that $g_{2} \in(0,1)$, so the elation associated with receiving more than expected is positive but less important than the associated material utility, then our estimate $\widetilde{\lambda}_{2}=1.724$ implies that $(15) \in(1.862,2.724)$. This matches previous estimates of the coefficient of loss aversion, and is broadly in line with Crawford and Meng (2009)'s baseline estimate of the ratio of the slopes of total utility in the loss and gain domains of 1.715 in the context of the loss aversion of taxi drivers around rational expectationsbased daily income and hours targets which are fixed at the point of optimization.

\section{Conclusion}

People compete all the time, e.g., for: promotions; bonuses; professional partnerships; elected positions; social status; and sporting trophies. In these situations the competitors exert effort to improve their prospects of success, and clear winners and losers emerge. Our results indicate that winners are elated while losers are disappointed, and that disappointment is the stronger emotion. In particular, we show that when our experimental subjects compete in a sequentialmove real effort competition, they are loss averse around an endogenous reference point given by their expected payoff. A person's reference point is conditioned on her own work effort and that of her rival, and adjusts essentially instantaneously to the effort choices. Disappointment aversion creates a discouragement effect, whereby a competitor slacks off when her rival works hard.

We hope that our theoretical model and empirical findings will provide a useful building block when predicting how people will behave in competitive situations. Furthermore, the findings may be helpful to principals when designing competitive environments. For example, employers will want to know how much they need to compensate employees for the expected disappointment implicit in different types of compensation schemes. They will also be interested in the degree to which a given compensation structure might impact on employees' work efforts, for example by creating asymmetries with some employees exerting a lot of effort and others becoming discouraged.

Finally, we believe that the novel real effort slider task we developed for the purposes of this study will prove valuable to researchers running real effort experiments in other settings in which precise quantification of preference and cost parameters is important. 


\section{Appendix}

\section{A Proofs}

\section{A.1 Proof of Proposition 2}

Using (1) and (7),

$$
E U_{2}\left(e_{2}, e_{1}\right)=v\left(\frac{e_{2}-e_{1}+\gamma}{2 \gamma}\right)-\lambda_{2} v\left(\frac{\gamma^{2}-\left(e_{2}-e_{1}\right)^{2}}{4 \gamma^{2}}\right)-C_{2}\left(e_{2}\right) .
$$

We use a proof by contradiction. Suppose that when $e_{1}$ increases from $e_{11}$ to $e_{12}>e_{11}$, the Second Mover's optimal effort $e_{2}^{*}$ increases from $e_{21}^{*}$ to $e_{22}^{*}>e_{21}^{*}$. By the optimality of the Second Mover's effort choices

$$
\left[E U_{2}\left(e_{21}^{*}, e_{11}\right)-E U_{2}\left(e_{22}^{*}, e_{11}\right)\right]+\left[E U_{2}\left(e_{22}^{*}, e_{12}\right)-E U_{2}\left(e_{21}^{*}, e_{12}\right)\right] \geq 0 .
$$

Using (16), we get the following:

$$
\begin{aligned}
& E U_{2}\left(e_{21}^{*}, e_{11}\right)-E U_{2}\left(e_{21}^{*}, e_{12}\right)=v\left(\frac{-e_{11}+e_{12}}{2 \gamma}\right)+\lambda_{2} v\left(\frac{\left(e_{21}^{*}-e_{11}\right)^{2}-\left(e_{21}^{*}-e_{12}\right)^{2}}{4 \gamma^{2}}\right) \\
& E U_{2}\left(e_{22}^{*}, e_{12}\right)-E U_{2}\left(e_{22}^{*}, e_{11}\right)=v\left(\frac{-e_{12}+e_{11}}{2 \gamma}\right)+\lambda_{2} v\left(\frac{\left(e_{22}^{*}-e_{12}\right)^{2}-\left(e_{22}^{*}-e_{11}\right)^{2}}{4 \gamma^{2}}\right) .
\end{aligned}
$$

Thus

$$
(17)=\frac{\lambda_{2} v}{2 \gamma^{2}}\left(-e_{21}^{*} e_{11}+e_{21}^{*} e_{12}-e_{22}^{*} e_{12}+e_{22}^{*} e_{11}\right)=\frac{\lambda_{2} v}{2 \gamma^{2}}\left(e_{21}^{*}-e_{22}^{*}\right)\left(e_{12}-e_{11}\right)<0
$$

given $\lambda_{2}>0$ for a disappointment averse Second Mover, which contradicts (17) $\geq 0$ from above.

Note that if there are multiple optima, the proof extends naturally to show that the highest optimal effort in response to $e_{12}$ must lie weakly below the lowest in response to $e_{11}$.

\section{A.2 Proof of Proposition 3}

Using (9) and (16),

$$
\begin{aligned}
\frac{\partial E U_{2}\left(e_{2}, e_{1}\right)}{\partial e_{2}} & =\frac{v}{2 \gamma}+\frac{\lambda_{2} v\left(e_{2}-e_{1}\right)}{2 \gamma^{2}}-b-c e_{2} \\
\frac{\partial^{2} E U_{2}\left(e_{2}, e_{1}\right)}{\partial e_{2}^{2}} & =\frac{\lambda_{2} v}{2 \gamma^{2}}-c .
\end{aligned}
$$

We assume that $2 \gamma^{2} c-\lambda_{2} v>0$, so the objective function is strictly concave.

Suppose first that the action space $\mathcal{A}$ is continuous. The first-order condition gives the 
following reaction function:

$$
e_{2}^{*}\left(e_{1}\right)= \begin{cases}\bar{e} & \text { if } e_{1}<\frac{\gamma v+\lambda_{2} v \bar{e}-2 \gamma^{2}(b+c \bar{e})}{\lambda_{2} v} \\ \frac{\gamma v-\lambda_{2} v e_{1}-2 \gamma^{2} b}{2 \gamma^{2} c-\lambda_{2} v} \in[0, \bar{e}] & \text { if } e_{1} \in\left[\frac{\gamma v+\lambda_{2} v \bar{e}-2 \gamma^{2}(b+c \bar{e})}{\lambda_{2} v}, \frac{\gamma v-2 \gamma^{2} b}{\lambda_{2} v}\right] . \\ 0 & \text { if } e_{1}>\frac{\gamma v-2 \gamma^{2} b}{\lambda_{2} v}\end{cases}
$$

Given $\lambda_{2}>0$ and $2 \gamma^{2} c-\lambda_{2} v>0$, in the interior $\frac{d e_{2}^{*}}{d e_{1}}$ is clearly strictly negative and strictly decreasing in $\lambda_{2}$ and $v$.

Suppose second that the action space $\mathcal{A}$ is discrete. Take any $e_{2} \in \mathcal{A}$ for which there exists a higher effort which is a best response to some $e_{1} \in[0, \bar{e}]$ and a lower effort with the same property. Let $e_{2}^{+}$be the next highest effort in $\mathcal{A}$ and let $e_{2}^{-}$be the next lowest effort in $\mathcal{A}$. Using (9) and (16), $E U_{2}\left(e_{2}^{+}, e_{1}\right)-E U_{2}\left(e_{2}, e_{1}\right)$

$$
\begin{aligned}
& =\frac{v\left(e_{2}^{+}-e_{2}\right)}{2 \gamma}+\lambda_{2} v\left(\frac{\left(e_{2}^{+}-e_{1}\right)^{2}-\left(e_{2}-e_{1}\right)^{2}}{4 \gamma^{2}}\right)-b\left(e_{2}^{+}-e_{2}\right)-\frac{c\left(\left(e_{2}^{+}\right)^{2}-e_{2}^{2}\right)}{2} \\
& =\frac{\left(2 \gamma v-4 \gamma^{2} b\right)\left(e_{2}^{+}-e_{2}\right)}{4 \gamma^{2}}+\left(\frac{\lambda_{2} v-2 \gamma^{2} c}{4 \gamma^{2}}\right)\left(\left(e_{2}^{+}\right)^{2}-e_{2}^{2}\right)-\left(\frac{\lambda_{2} v}{4 \gamma^{2}}\right) 2 e_{1}\left(e_{2}^{+}-e_{2}\right) .
\end{aligned}
$$

The cut-off $e_{1}$ at which $E U_{2}\left(e_{2}^{+}, e_{1}\right)=E U_{2}\left(e_{2}, e_{1}\right)$ is given by

$$
\breve{e}_{1}\left(e_{2}^{+}, e_{2}\right)=\frac{2 \gamma v-4 \gamma^{2} b}{2 \lambda_{2} v}-\left(\frac{2 \gamma^{2} c-\lambda_{2} v}{\lambda_{2} v}\right)\left(\frac{e_{2}^{+}+e_{2}}{2}\right) .
$$

Given $\lambda_{2}>0$ and $2 \gamma^{2} c-\lambda_{2} v>0$ by assumption, the cut-offs are strictly decreasing in the Second Mover's effort. From Proposition 2, best responses are (weakly) falling in $e_{1}$. Thus if $e_{1}$ was continuous but $e_{2}$ was discrete, the cut-offs would represent the points at which the Second Mover's reaction function jumped down. As both are discrete, the cut-offs define the Second Mover's reaction function in the interior: $e_{2}$ is a best response for the Second Mover for and only for any $e_{1} \in\left[\breve{e}_{1}\left(e_{2}^{+}, e_{2}\right), \breve{e}_{1}\left(e_{2}, e_{2}^{-}\right)\right] \cap \mathcal{A}$. The range $\left[\breve{e}_{1}\left(e_{2}^{+}, e_{2}\right), \breve{e}_{1}\left(e_{2}, e_{2}^{-}\right)\right]$is of size

$$
\breve{e}_{1}\left(e_{2}, e_{2}^{-}\right)-\breve{e}_{1}\left(e_{2}^{+}, e_{2}\right)=\left(\frac{2 \gamma^{2} c-\lambda_{2} v}{\lambda_{2} v}\right)\left(\frac{e_{2}^{+}-e_{2}^{-}}{2}\right),
$$

which is strictly decreasing in $\lambda_{2}$ and $v$.

That the cut-offs are strictly decreasing in $e_{2}$ is the discrete case analogue of the reaction function being strictly downward sloping in the continuous case. That the size of the ranges between the cut-offs is strictly decreasing in $\lambda_{2}$ and $v$ is the discrete case analogue of the reaction function becoming strictly steeper in $\lambda_{2}$ and $v$ in the continuous case. Note also the functional form similarity: supposing that the permitted $e_{2}$ 's increase in unit steps, $\frac{e_{2}^{+}+e_{2}}{2}=e_{2}+\frac{1}{2}$, so the rate of change of $\breve{e}_{1}\left(e_{2}^{+}, e_{2}\right)$ with respect to $e_{2}$ is the inverse of the slope of the reaction function in the continuous case. 


\section{B MSM: Further Details}

\section{B.1 Construction of Simulated Samples}

The construction of each simulated sample is conditional on the First Mover efforts and prizes observed in the actual sample. Additionally we make random draws which will later be used to construct the unobservables appearing in the structural model. Specifically, for each simulated sample $s=1, \ldots, S$ we construct matrices of dimensions $N \times 1, N \times 1$ and $N \times 10$, denoted $Q 1_{s}$, $Q 2_{s}$ and $Q 3_{s}$ respectively. Each element of $Q 1_{s}, Q 2_{s}$ and $Q 3_{s}$ contains a random draw from a standard uniform distribution. These matrices are held fixed throughout the estimation. ${ }^{25}$ Given a trial parameter vector $\theta_{t}$, the effort choice of the $n^{\text {th }}$ Second Mover in the $r^{\text {th }}$ round of the $s^{\text {th }}$ sample is determined as follows:

1. The Second Mover is assigned values of the unobservables $\lambda_{2, n}, \mu_{n}$ and $\pi_{n, r}$ in accordance with the distributional assumptions made in Section 4.3.1. Draws from the normal distribution are found by transforming $Q 1_{s}$ as follows:

$$
\lambda_{2, n}=\widetilde{\lambda}_{2}+\sigma_{\lambda} \Phi^{-1}\left(Q 1_{s, n}\right),
$$

where $\Phi^{-1}$ denotes the inverse of the standard normal distribution function. Draws from the Weibull distribution are obtained by transforming $Q 2_{s}$ and $Q 3_{s}$ as follows:

$$
\begin{aligned}
\mu_{n} & =\phi_{\mu}\left(-\ln \left(Q 2_{s, n}\right)\right)^{1 / \varphi_{\mu}} \\
\pi_{n, r} & =\phi_{\pi}\left(-\ln \left(Q 3_{s, n, r}\right)\right)^{1 / \varphi_{\pi}}
\end{aligned}
$$

The values of the parameters $\tilde{\lambda}_{2}, \sigma_{\lambda}, \varphi_{\mu}, \varphi_{\pi}, \phi_{\mu}$ and $\phi_{\pi}$ are obtained by extracting the relevant elements of $\theta_{t}$.

2. Given the assigned values of $\lambda_{2, n}, \mu_{n}$ and $\pi_{n, r}$ and the remaining parameters of the cost of effort function, $b, \kappa$ and $\delta_{r}$ for $r=2, \ldots, 10$ as given by $\theta_{t}$, the expected utility associated with each feasible Second Mover effort is computed using (7), (9) and (13).

3. The Second Mover is assigned the effort choice corresponding to the highest expected utility.

Steps 1-3 are repeated for each of the 10 rounds, the $N$ Second Movers and the $S$ simulated samples. Note that by comparing the expected utilities associated with each of the 49 feasible effort choices we fully account for the discreteness of effort. Additionally, the method of simulation does not rely on the objective function being well behaved.

\footnotetext{
${ }^{25}$ Thus as the trial parameter vector $\theta_{t}$ is adjusted the simulated samples vary only due to the change in $\theta_{t}$ and not due to variation in the underlying random draws. This is necessary to ensure convergence of the estimation routine (Stern, 1997).
} 


\section{B.2 Asymptotic Properties and Numerical Methods}

Under the conditions in Pakes and Pollard (1989), $\widehat{\theta}$ is consistent and asymptotically normal. Specifically, with $S$ fixed,

$$
\sqrt{N}(\widehat{\theta}-\theta) \stackrel{d}{\rightarrow} N\left(0, \frac{S+1}{S}\left(D^{\prime} W D\right)^{-1} D^{\prime} W \Omega W D\left(D^{\prime} W D\right)^{-1}\right) \text { as } N \rightarrow \infty
$$

where $\Omega=N \operatorname{cov}(M)$ is the covariance matrix of the sample moments normalized by the sample size, $W=\operatorname{plim}\left(W_{N}\right)$ and

$$
D=\left.\frac{1}{S} \sum_{s=1}^{S} \frac{d M_{s}\left(\theta_{t}\right)}{d \theta_{t}^{\prime}}\right|_{\theta_{t}=\theta}
$$

When implementing MSM, we use $S=30$ simulated samples and therefore simulate 17700 pairings when using $N=59$, and we estimate the weight matrix $W_{N}$ using 5000 bootstrapped samples each containing $N$ Second Movers sampled with replacement from the original sample.

The term $\frac{1}{S} \sum_{s=1}^{S} M_{s}\left(\theta_{t}\right)$ appearing in $J\left(\theta_{t}\right)$ in (14) is not a continuous function of the parameter vector $\theta_{t}$ as small changes in $\theta_{t}$ may cause discrete changes in some Second Movers' optimal effort choices. Consequently gradient and Hessian based optimization methods are unsuitable for minimizing $J\left(\theta_{t}\right)$. Instead we use Simulated Annealing in the form suggested by Goffe et al. (1994) to solve for the MSM estimates.

\section{B.3 Moments and Goodness of Fit}




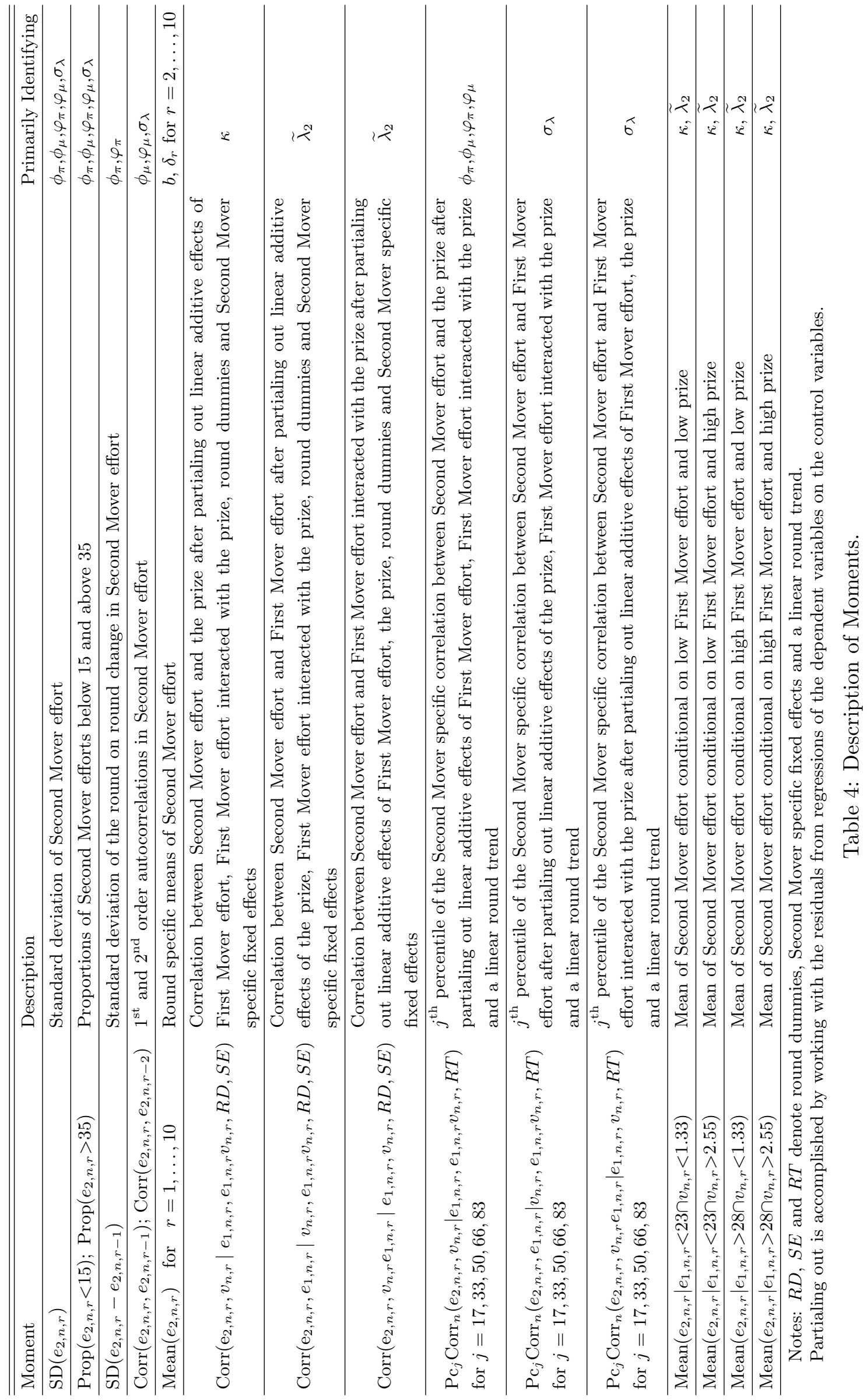




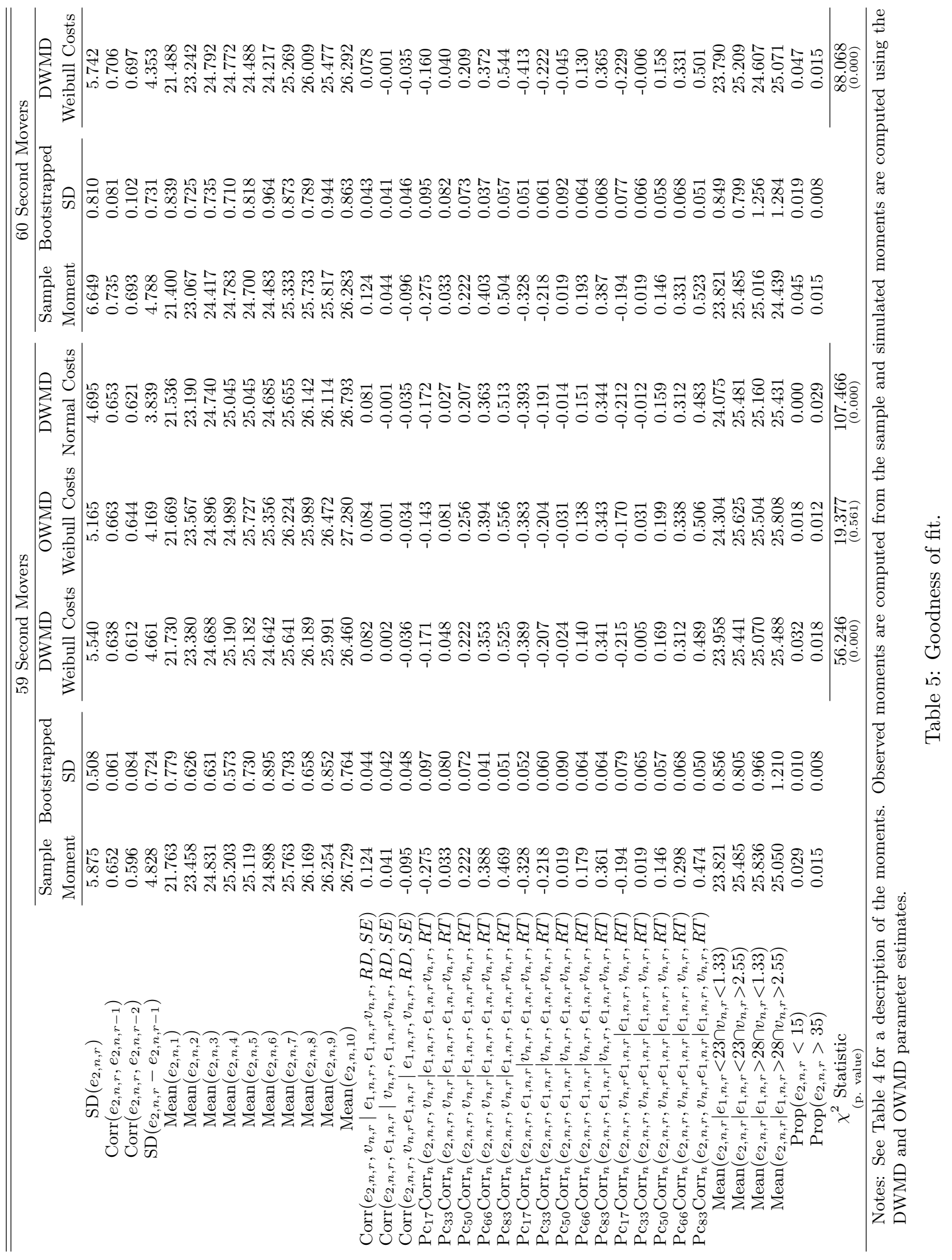




\section{Experimental Instructions}

Please open the brown envelope you have just collected. I am reading from the four page instructions sheet which you will find in your brown envelope. [Open brown envelope]

Thank you for participating in this session. There will be a number of pauses for you to ask questions. During such a pause, please raise your hand if you want to ask a question. Apart from asking questions in this way, you must not communicate with anybody in this room. Please now turn off mobile phones and any other electronic devices. These must remain turned off for the duration of this session. Are there any questions?

You have been allocated to a computer booth according to the number on the card you selected as you came in. You must not look into any of the other computer booths at any time during this session. As you came in you also selected a white sealed envelope. Please now open your white envelope. [Open white envelope]

Each white envelope contains a different four digit Participant ID number. To ensure anonymity, your actions in this session are linked to this Participant ID number and at the end of this session you will be paid by Participant ID number. You will be paid a show up fee of $£ 4$ together with any money you accumulate during this session. The amount of money you accumulate will depend partly on your actions, partly on the actions of others and partly on chance. All payments will be made in cash in another room. Neither I nor any of the other participants will see how much you have been paid. Please follow the instructions that will appear shortly on your computer screen to enter your four digit Participant ID number. [Enter four digit Participant ID number] Please now return your Participant ID number to its envelope, and keep this safe as your Participant ID number will be required for payment at the end.

This session consists of 2 practice rounds, for which you will not be paid, followed by 10 paying rounds with money prizes. In each round you will undertake an identical task lasting 120 seconds. The task will consist of a screen with 48 sliders. Each slider is initially positioned at 0 and can be moved as far as 100. Each slider has a number to its right showing its current position. You can use the mouse in any way you like to move each slider. You can readjust the position of each slider as many times as you wish. Your "points score" in the task will be the number of sliders positioned at exactly 50 at the end of the 120 seconds. Are there any questions?

Before the first practice round, you will discover whether you are a "First Mover" or a "Second Mover". You will remain either a First Mover or a Second Mover for the entirety of this session.

In each round, you will be paired. One pair member will be a First Mover and the other will be a Second Mover. The First Mover will undertake the task first, and then the Second Mover will undertake the task. The Second Mover will see the First Mover's points score before starting the task.

In each paying round, there will be a prize which one pair member will win. Each pair's prize will be chosen randomly at the beginning of the round and will be between $£ 0.10$ and $£ 3.90$. The winner of the prize will depend on the difference between the First Mover's and the Second Mover's points scores and some element of chance. If the points scores are the same, 
each pair member will have a $50 \%$ chance of winning the prize. If the points scores are not the same, the chance of winning for the pair member with the higher points score increases by 1 percentage point for every increase of 1 in the difference between the points scores, while the chance of winning for the pair member with the lower points score correspondingly decreases by 1 percentage point. The table at the end of these instructions gives the chance of winning for any points score difference. Please look at this table now. [Look at table] Are there any questions?

During each task, a number of pieces of information will appear at the top of your screen, including the time remaining, the round number, whether you are a First Mover or a Second Mover, the prize for the round and your points score in the task so far. If you are a Second Mover, you will also see the points score of the First Mover you are paired with.

After both pair members have completed the task, each pair member will see a summary screen showing their own points score, the other pair member's points score, their probability of winning, the prize for the round and whether they were the winner or the loser of the round.

We will now start the first of the two practice rounds. In the practice rounds, you will be paired with an automaton who behaves randomly. Before we start, are there any questions? Please look at your screen now. [First practice round] Before we start the second practice round, are there any questions? Please look at your screen now. [Second practice round] Are there any questions?

The practice rounds are finished. We will now move on to the 10 paying rounds. In every paying round, each First Mover will be paired with a Second Mover. The pairings will be changed after every round and pairings will not depend on your previous actions. You will not be paired with the same person twice. Furthermore, the pairings are done in such a way that the actions you take in one round cannot affect the actions of the people you will be paired with in later rounds. This also means that the actions of the person you are paired with in a given round cannot be affected by your actions in earlier rounds. (If you are interested, this is because you will not be paired with a person who was paired with someone who had been paired with you, and you will not be paired with a person who was paired with someone who had been paired with someone who had been paired with you, and so on.) Are there any questions?

We will now start the 10 paying rounds. There will be no pauses between the rounds. Before we start the paying rounds, are there any remaining questions? There will be no further opportunities to ask questions. Please look at your screen now. [10 paying rounds]

The session is now complete. Your total cash payment, including the show up fee, is displayed on your screen. Please leave the room one by one when asked to do so to receive your payment. Remember to bring the envelope containing your four digit Participant ID number with you but please leave all other materials on your desk. Thank you for participating. 


\begin{tabular}{|c|c|c|}
\hline $\begin{array}{l}\text { Difference in } \\
\text { points scores }\end{array}$ & \begin{tabular}{|c|} 
Chance of winning prize \\
for Mover with higher score
\end{tabular} & $\begin{array}{l}\text { Chance of winning prize } \\
\text { for Mover with lower score }\end{array}$ \\
\hline 0 & $50 \%$ & $50 \%$ \\
\hline 1 & $51 \%$ & $49 \%$ \\
\hline 2 & $52 \%$ & $48 \%$ \\
\hline 3 & $53 \%$ & $47 \%$ \\
\hline 4 & $54 \%$ & $46 \%$ \\
\hline 5 & $55 \%$ & $45 \%$ \\
\hline 6 & $56 \%$ & $44 \%$ \\
\hline 7 & $57 \%$ & $43 \%$ \\
\hline 8 & $58 \%$ & $42 \%$ \\
\hline 9 & $59 \%$ & $41 \%$ \\
\hline 10 & $60 \%$ & $40 \%$ \\
\hline 11 & $61 \%$ & $39 \%$ \\
\hline 12 & $62 \%$ & $38 \%$ \\
\hline 13 & $63 \%$ & $37 \%$ \\
\hline 14 & $64 \%$ & $36 \%$ \\
\hline 15 & $65 \%$ & $35 \%$ \\
\hline 16 & $66 \%$ & $34 \%$ \\
\hline 17 & $67 \%$ & $33 \%$ \\
\hline 18 & $68 \%$ & $32 \%$ \\
\hline 19 & $69 \%$ & $31 \%$ \\
\hline 20 & $70 \%$ & $30 \%$ \\
\hline 21 & $71 \%$ & $29 \%$ \\
\hline 22 & $72 \%$ & $28 \%$ \\
\hline 23 & $73 \%$ & $27 \%$ \\
\hline 24 & $74 \%$ & $26 \%$ \\
\hline 25 & $75 \%$ & $25 \%$ \\
\hline 26 & $76 \%$ & $24 \%$ \\
\hline 27 & $77 \%$ & $23 \%$ \\
\hline 28 & $78 \%$ & $22 \%$ \\
\hline 29 & $79 \%$ & $21 \%$ \\
\hline 30 & $80 \%$ & $20 \%$ \\
\hline 31 & $81 \%$ & $19 \%$ \\
\hline 32 & $82 \%$ & $18 \%$ \\
\hline 33 & $83 \%$ & $17 \%$ \\
\hline 34 & $84 \%$ & $16 \%$ \\
\hline 35 & $85 \%$ & $15 \%$ \\
\hline 36 & $86 \%$ & $14 \%$ \\
\hline 37 & $87 \%$ & $13 \%$ \\
\hline 38 & $88 \%$ & $12 \%$ \\
\hline 39 & $89 \%$ & $11 \%$ \\
\hline 40 & $90 \%$ & $10 \%$ \\
\hline 41 & $91 \%$ & $9 \%$ \\
\hline 42 & $92 \%$ & $8 \%$ \\
\hline 43 & $93 \%$ & $7 \%$ \\
\hline 44 & $94 \%$ & $6 \%$ \\
\hline 45 & $95 \%$ & $5 \%$ \\
\hline 46 & $96 \%$ & $4 \%$ \\
\hline 47 & $97 \%$ & $3 \%$ \\
\hline 48 & $98 \%$ & $2 \%$ \\
\hline 49 & \multicolumn{2}{|c|}{ Not possible as there are only 48 sliders } \\
\hline 50 & \multicolumn{2}{|c|}{ Not possible as there are only 48 sliders } \\
\hline
\end{tabular}

Table 6: Chance of winning in a given round. 


\section{References}

Abeler, J., Falk, A., Götte, L., and Huffman, D. (2009). Reference Points and Effort Provision. IZA, Discussion Paper 3939

Altonji, J. and Segal, L. (1996). Small-Sample Bias in GMM Estimation of Covariance Structures. Journal of Business and Economic Statistics, 14(3): 353-366

Barberis, N., Huang, M., and Thaler, R.H. (2006). Individual Preferences, Monetary Gambles, and Stock Market Participation: A Case for Narrow Framing. American Economic Review, 96(4): 1069-1090

Battigalli, P. and Dufwenberg, M. (2009). Dynamic Psychological Games. Journal of Economic Theory, 144(1): 1-35

Bell, D.E. (1985). Disappointment in Decision Making under Uncertainty. Operations Research, 33(1): 1-27

Brüggen, A. and Strobel, M. (2007). Real Effort versus Chosen Effort in Experiments. Economics Letters, 96(2): 232-236

Bull, C., Schotter, A., and Weigelt, K. (1987). Tournaments and Piece Rates: An Experimental Study. Journal of Political Economy, 95(1): 1-33

Burrows, P. and Loomes, G. (1994). The Impact of Fairness on Bargaining Behaviour. Empirical Economics, 19(2): 201-221

Camerer, C., Babcock, L., Loewenstein, G., and Thaler, R. (1997). Labor Supply of New York City Cabdrivers: One Day At A Time. Quarterly Journal of Economics, 112(2): 407-441

Carpenter, J., Matthews, P.H., and Schirm, J. (2007). Tournaments and Office Politics: Evidence from a Real Effort Experiment. IZA, Discussion Paper 2972, forthcoming in American Economic Review

Charness, G. and Villeval, M.C. (2009). Cooperation and Competition in Intergenerational Experiments in the Field and the Laboratory. American Economic Review, 99(3): 956-978

Che, Y.K. and Gale, I. (2000). Difference-Form Contests and the Robustness of All-Pay Auctions. Games and Economic Behavior, 30(1): 22-43

Choi, S., Fisman, R., Gale, D., and Kariv, S. (2007). Consistency and Heterogeneity of Individual Behavior under Uncertainty. American Economic Review, 97(5): 1921-1938

Chow, C.W. (1983). The Effects of Job Standard Tightness and Compensation Scheme on Performance: An Exploration of Linkages. Accounting Review, 58(4): 667-685

Cooper, R., DeJong, D.V., Forsythe, R., and Ross, T.W. (1996). Cooperation without Reputation: Experimental Evidence from Prisoner's Dilemma Games. Games and Economic Behavior, 12(2): 187-218

Crawford, V.P. and Meng, J. (2009). New York City Cabdrivers' Labor Supply Revisited: Reference-Dependent Preferences with Rational-Expectations Targets for Hours and Income. UCSD, Mimeo

Dal Bó, P. (2005). Cooperation under the Shadow of the Future: Experimental Evidence from Infinitely Repeated Games. American Economic Review, 95(5): 1591-1604

DellaVigna, S. (2009). Psychology and Economics: Evidence from the Field. Journal of Economic Literature, 47(2): 315-372

Delquié, P. and Cillo, A. (2006a). Disappointment without Prior Expectation: A Unifying Perspective on Decision under Risk. Journal of Risk and Uncertainty, 33(3): 197-215

Delquié, P. and Cillo, A. (2006b). Expectations, Disappointment, and Rank-Dependent Probability Weighting. Theory and Decision, 60(2): 193-206

Doran, K.B. (2009). Reference Points, Expectations, and Heterogeneous Daily Labor Supply. University of Notre Dame, Mimeo

Falk, A. and Fehr, E. (2003). Why Labour Market Experiments? Labour Economics, 10(4): 399-406

Fischbacher, U. (2007). z-Tree: Zurich Toolbox for Ready-Made Economic Experiments. Experimental Economics, 10(2): 171-178 
Geanakoplos, J., Pearce, D., and Stacchetti, E. (1989). Psychological Games and Sequential Rationality. Games and Economic Behavior, 1(1): 60-79

Gibson, J. (1996). Thomas Hardy: A Literary Life. Palgrave

Gill, D. and Stone, R. (2009). Fairness and Desert in Tournaments. University of Southampton, Mimeo

Gneezy, U., Niederle, M., and Rustichini, A. (2003). Performance in Competitive Environments: Gender Differences. Quarterly Journal of Economics, 118(3): 1049-1074

Goffe, W.L., Ferrier, G.D., and Rogers, J. (1994). Global Optimization of Statistical Functions with Simulated Annealing. Journal of Econometrics, 60(1-2): 65-99

Gul, F. (1991). A Theory of Disappointment Aversion. Econometrica, 59(3): 667-686

Hoffman, E., McCabe, K., Shachat, K., and Smith, V. (1994). Preferences, Property Rights, and Anonymity in Bargaining Games. Games and Economic Behavior, 7(3): 346-380

Kahneman, D. (2003). A Psychological Perspective on Economics. American Economic Review: Papers and Proceedings, 93(2): 162-168

Kahneman, D. and Tversky, A. (1979). Prospect Theory: An Analysis of Decision under Risk. Econometrica, 47(2): 263-291

Kahneman, D. and Tversky, A., editors (2000). Choices, Values, and Frames. Cambridge University Press

Köszegi, B. and Rabin, M. (2006). A Model of Reference-Dependent Preferences. Quarterly Journal of Economics, 121(4): 1133-1165

Köszegi, B. and Rabin, M. (2007). Reference-Dependent Risk Attitudes. American Economic Review, 97(4): 1047-1073

Konow, J. (2000). Fair Shares: Accountability and Cognitive Dissonance in Allocation Decisions. American Economic Review, 90(4): 1072-1091

Loomes, G. and Sugden, R. (1986). Disappointment and Dynamic Consistency in Choice under Uncertainty. Review of Economic Studies, 53(2): 271-282

Loomes, G. and Sugden, R. (1987). Testing for Regret and Disappointment in Choice under Uncertainty. Economic Journal, 97: 118-129

McFadden, D. (1989). A Method of Simulated Moments for Estimation of Discrete Response Models without Numerical Integration. Econometrica, 57(5): 995-1026

Mellers, B., Schwartz, A., and Ritov, I. (1999). Emotion-Based Choice. Journal of Experimental Psychology: General, 128(3): 332-345

Niederle, M. and Vesterlund, L. (2007). Do Women Shy Away from Competition? Do Men Compete Too Much? Quarterly Journal of Economics, 122(3): 1067-1101

Pakes, A. and Pollard, D. (1989). Simulation and the Asymptotics of Optimization Estimators. Econometrica, 57(5): 1027-57

Read, D., Loewenstein, G., and Rabin, M. (1999). Choice Bracketing. Journal of Risk and Uncertainty, 19(1-3): 171-197

Shalev, J. (2000). Loss Aversion Equilibrium. International Journal of Game Theory, 29(2): 269-287

Sonsino, D. (2008). Disappointment Aversion in Internet Bidding-Decisions. Theory and Decision, 64(1-2): 363-393

Stern, S. (1997). Simulation-Based Estimation. Journal of Economic Literature, 35(4): 20062039

Sutter, M. and Weck-Hannemann, H. (2003). Taxation and the Veil of Ignorance - A Real Effort Experiment on the Laffer Curve. Public Choice, 115(1-2): 217-240

Tversky, A. and Kahneman, D. (1992). Advances in Prospect Theory: Cumulative Representation of Uncertainty. Journal of Risk and Uncertainty, 5(4): 297-323

van Dijk, F., Sonnemans, J., and van Winden, F. (2001). Incentive Systems in a Real Effort Experiment. European Economic Review, 45(2): 187-214

van Dijk, W.W., van der Pligt, J., and Zeelenberg, M. (1999). Effort Invested in Vain: The Impact of Effort on the Intensity of Disappointment and Regret. Motivation and Emotion, 23(3): 203-220 